\title{
Arc Regulates Experience-Dependent Persistent Firing Patterns in Frontal Cortex
}

\author{
Ming Ren, ${ }^{1}$ Vania Cao, ${ }^{1}$ Yizhou Ye, ${ }^{1}$ Husseini K. Manji, ${ }^{2}$ and Kuan Hong Wang ${ }^{1}$ \\ ${ }^{1}$ Unit on Neural Circuits and Adaptive Behaviors, Genes Cognition and Psychosis Program, and ${ }^{2}$ Laboratory of Molecular Pathophysiology and \\ Experimental Therapeutics, Mood and Anxiety Disorders Program, National Institute of Mental Health, National Institutes of Health, Bethesda, Maryland \\ 20892
}

The brain encodes information about past experience in specific populations of neurons that communicate with one another by firing action potentials. Studies of experience-dependent neural plasticity have largely focused on individual synaptic changes in response to neuronal input. Indicative of the neuronal output transmitted to downstream neurons, persistent firing patterns are affected by prior experience in selective neuronal populations. However, little is known about the molecular and cellular mechanisms by which experience-related persistent firing patterns are regulated in specific neuronal populations. Using frontal cortical slices prepared from transgenic mice carrying a fluorescent reporter of Arc gene expression, this study investigates how behavioral experience and the activity-regulated Arc gene affect patterns of neuronal firing. We found that motor training increases Arc expression in subsets of excitatory neurons. Those neurons exhibit persistent firing in contrast to Arc-negative neurons from the same mice or neurons from the untrained mice. Furthermore, in mice carrying genetic deletion of $A r c$, the frontal cortical circuitry is still in place to initiate experiencedependent gene expression, but the level of persistent firing thereafter is diminished. Finally, our results showed that the emergence of persistent activity is associated with Arc-dependent changes in the function of NMDA-type glutamate receptors, rather than changes in AMPA-type receptors or membrane excitability. Our findings therefore reveal an Arc-dependent molecular pathway by which geneexperience interaction regulates the emergence of persistent firing patterns in specific neuronal populations.

Key words: Arc/Arg3.1; experience dependent; frontal cortex; NMDA receptor; persistent activity

\section{Introduction}

Our brain encodes information about past experience in specific populations of neurons that communicate with one another by firing action potentials (Silva et al., 2009; Barth and Poulet, 2012). Previous studies of experience-dependent plasticity have focused on how individual synapses respond to activity input (Luscher and Malenka, 2012). Persistent firing activity, defined as a sustained increase in action potential discharge lasting from hundreds of milliseconds to seconds, reflects neuronal output to downstream neurons (Wang, 2001; Major and Tank, 2004). In the frontal cortex, persistent activity is considered a key neurophysiological substrate underlying information retention (Fuster, 2001; Miller and Cohen, 2001). While behavioral studies have

\footnotetext{
Received Jan. 14, 2014; revised March 31, 2014; accepted April 1, 2014.

Author contributions: M.R., V.C., H.K.M., and K.H.W. designed research; M.R., V.C., and Y.Y. performed research; M.R. and K.H.W. analyzed data; M.R., Y.Y., H.K.M., and K.H.W. wrote the paper.

This work was supported by the National Institute of Mental Health (NIMH) Intramural Research Program (M.R., V.C., Y.Y., H.K.M., K.H.W.) and a National Alliance for Research on Schizophrenia and Depression Young Investigator Award (M.R.). We thank T.R. Insel, D.R. Weinberger, P.S. Wang, M.E. Greenberg, and W.G. Chen for their critical reading of the manuscript and helpful discussions, and E.J. Sherman for technical editing. K.H.W. acknowledges the support of the NIMH Division of Intramural Research Programs and the Genes Cognition and Psychosis Program.

The authors declare no competing financial interests.

Correspondence should be addressed to Kuan Hong Wang at the above address. E-mail: wkuan@mail.nih.gov.

Husseini K. Manji's present address: Johnson \& Johnson Pharmaceutical Research and Development, Titusville, NJ 08560.

DOI:10.1523/JNEUROSCI.0167-14.2014

Copyright $\odot 2014$ the authors $\quad 0270-6474 / 14 / 336583-13 \$ 15.00 / 0$
}

demonstrated that experience affects persistent activity in selective populations of neurons in the frontal cortex (TakeharaNishiuchi and McNaughton, 2008; Histed et al., 2009; Erlich et al., 2011), little is as yet known about the molecular and cellular mechanisms by which those experience-related persistent firing patterns are regulated.

Researchers seeking to elucidate the cellular and molecular processes underlying persistent activity have generally used rodent frontal slices, which preserve the signature electrophysiological properties of persistent activity in vivo and provide better experimental access to individual neurons (Tseng and O'Donnell, 2005; Durstewitz and Gabriel, 2007; Sidiropoulou et al., 2009; Thuault et al., 2013). These studies have identified a number of neural transmitter receptors and ion channels, including NMDA receptor (NMDAR) and dopamine D1-type receptor (D1R), involved in persistent activity. Although individual neurons in frontal cortical slices exhibit varying degrees of persistent activity (Durstewitz and Gabriel, 2007), whether prior experience regulates the persistent activity in those neurons remains unknown.

In rodents, training for a new motor task, such as running on a rotating rod, leads to pronounced activation of the frontal cortex (Holschneider et al., 2003; Costa et al., 2004). Whether motor training tasks affect persistent firing generated during subsequent circuit activities, however, has yet to be determined. When investigating this question in frontal cortical slices, the major challenge 
is distinguishing neurons activated by prior training experience from those unaffected by the experience in question. In this study, we focused on the activity-regulated cytoskeletonassociated protein (Arc/Arg3.1), which has been widely used as a marker for neurons activated by recent behavioral experience (Guzowski et al., 2005; Barth, 2007). Although Arc has been implicated in experience-dependent changes of synaptic AMPAtype glutamate receptors (AMPARs) in hippocampal and visual systems (Bramham et al., 2008; Shepherd and Bear, 2011), its role in persistent firing has not been investigated.

By imaging Arc promoter-driven GFP expression in a knock-in mouse line, we found that motor training induces Arc expression in subsets of frontal neurons. Those neurons preferentially support persistent activity compared with Arc-neurons from the same mice or neurons from the untrained mice. We then genetically deleted Arc and found that persistent activity diminishes. Finally, we demonstrate that the emergence of persistent firing is associated with Arc-dependent changes in the function of NMDARs, but not in AMPARs or membrane excitability. Together, our findings suggest that Arc regulates experience-related persistent firing patterns in frontal cortical neurons.

\section{Materials and Methods}

Experimental animals. All experimental procedures conformed to National Institutes of Health $(\mathrm{NIH})$ guidelines and were performed with the approval of the NIH Animal Care and Use Committee. The Arc-GFP knock-in mouse line generated in C57BL/6 background (Wang et al., 2006) of either sex was used in this study. All experiments were conducted in wild-type (WT), heterozygous (HET), or homozygous (HOM) Arc-GFP mice, as specified, at 2-3 months of age.

Behavioral experimental procedures. In the motor-training task, the standard computer-interfaced rotarod apparatus for mice (ENV-575M, MedAssociates) was used. In each trial, the mouse was initially placed on the still rotarod, which was then activated. The rotation speed, which increased from 4 to $40 \mathrm{rpm}$ gradually over a $300 \mathrm{~s}$ period, was recorded until the mouse was unable to keep up and fell. In early trials, mice typically fell off the rotarod at a low speed. By the end of a 45 min training session, trained mice were capable of running on the rotarod at a speed, on average, of $35 \mathrm{rpm}$. After this $45 \mathrm{~min}$ of motor-task training, all the trained mice were returned to home cages to rest for $1 \mathrm{~h}$ and $15 \mathrm{~min}$ before being subjected to the next experimental procedures. This resting period is required for expression of Arc-GFP to reach levels optimal for confocal imaging (Wang et al., 2006). For the sake of consistency, WT mice were treated the same, and untrained mice were left undisturbed in their home cages until the next experimental procedure. Mice in the handling group were placed on a stationary rotarod for $5 \mathrm{~min}$, then pulled down to the ground. This procedure was repeated for a total of 45 min as the same duration of motor training. Other housing and handling procedures were identical for all the mice, regardless of differences in genotype or training status.

To examine changes in running behavior over multiple days of training, mice were trained 10 trials a day for 3 consecutive days. Previous video analyses of this task suggested that on later days of training, mice position their footsteps closer to the top of the rod, which improves their balance and keeps them from slipping (Buitrago et al., 2004; Farr et al., 2006). In our study, mice were videotaped in the first two and last two trials of each day. We then analyzed the footstep positions of mice using video-tracking software (Tracker). The distance from the left rear paw to the top of the rod was measured every $2 \mathrm{~s}$ till the end of a trial. The average of foot positions recorded each day reflects the mouse running strategy on that day. All the behavioral experiments and analyses were performed on littermates blindly and without regard to genotypes.

Preparation of acute cortical slices. Coronal slices (250-300 $\mu \mathrm{m}$ thick) containing the frontal cortex (bregma, $0.5-1.5 \mathrm{~mm}$ ) were cut with a vibratome (Leica) in ice-cold, oxygenated $\left(95 \% \mathrm{O}_{2}\right.$ and $\left.5 \% \mathrm{CO}_{2}\right)$ artificial CSF (ACSF) containing the following (in mM): 222 sucrose, $2.5 \mathrm{KCl}$,
$1.2 \mathrm{NaH}_{2} \mathrm{PO}_{4}, 3 \mathrm{MgCl}_{2}, 0.5 \mathrm{CaCl}_{2}, 26 \mathrm{NaHCO}_{3}$, and 10 glucose. After cutting, slices were transferred into the recording oxygenated ACSF $\left(95 \% \mathrm{O}_{2}\right.$ and $5 \% \mathrm{CO}_{2}$ ) containing the following (in mM): $125 \mathrm{NaCl}, 25$ $\mathrm{NaHCO}_{3}, 10$ glucose, $3.5 \mathrm{KCl}, 1.25 \mathrm{NaH}_{2} \mathrm{PO}_{4}, 2 \mathrm{CaCl}_{2}, 1 \mathrm{MgCl}_{2}, \mathrm{pH}$ 7.45; osmolarity, $295 \pm 5 \mathrm{mOsm}$ ) and allowed to recover for $1 \mathrm{~h}$ at room temperature. These slices were then transferred to a standard recording chamber mounted on the Olympus confocal microscope (FV1000) stage, and maintained at $33-35^{\circ} \mathrm{C}$ for subsequent electrophysiological recordings.

Slice electrophysiology. In these mouse frontal cortical slices, individual pyramidal neurons in the superficial layers (II/III) of the Cg1 area were visualized through a $40 \times$ water-immersion objective, using infrareddifferential interference contrast video microscopy (QImaging), and recorded with whole-cell patch-clamp configuration. Patch pipettes $(6-8$ $\mathrm{M} \Omega$ ) were filled with the following (in $\mathrm{mM}$ ): $115 \mathrm{~K}$-gluconate, 10 HEPES, $2 \mathrm{MgCl}_{2}, 20 \mathrm{KCl}, 2 \mathrm{MgATP}, 2 \mathrm{Na}_{2}$-ATP, and 0.3 GTP, pH 7.3, $280 \pm 5$ mOsm. To block NMDAR activity in some of the recorded cells where indicated, MK-801 (1 mM) was added to the pipette solution.

To visualize patched cells under fluorescence confocal microscopy, we included the red fluorescent dye Alexa Fluor $594(10 \mu \mathrm{M})$ in the pipette solution. To target Arc-GFP+ neurons for recording, those neurons were identified in the green channel of the confocal microscope before initiating patch-clamp recording procedures. Recordings were then performed with Axopatch700B amplifiers (Molecular Devices). Signals were low-pass filtered at $10 \mathrm{kHz}$, digitized with a Digidata $1400 \mathrm{~A}$ (Axon) at 20 $\mathrm{kHz}$, and fed to a computer for off-line analysis with pCLAMP version 10.0 (Molecular Devices). Only cells with a seal resistance $>1 \mathrm{G} \Omega$ and a series resistance $<25 \mathrm{M} \Omega$ were used for analysis.

To measure persistent activity in frontal neurons, current-clamp recording was first established in the recording ACSF for $10 \mathrm{~min}$. Then, D1R agonist SKF38393 $(2 \mu \mathrm{M})$ and NMDA $(8 \mu \mathrm{M})$ were perfused into the recording chamber for 10-15 $\mathrm{min}$, while the current-clamp recording continued (Tseng and O'Donnell, 2005; Durstewitz and Gabriel, 2007). Once fluctuations in the membrane voltage and neuronal firing rate were stabilized, a 1 min membrane potential trace for each neuron was collected. These electrophysiological data were analyzed using Clampfit software (Molecular Devices) and custom-written scripts in Matlab (Mathworks). To determine the duration of each membrane depolarization event $(\Delta t)$, we established a threshold at $15 \mathrm{mV}$ above baseline membrane potential, then measured the time between initial upward and subsequent downward crossing of this threshold. The mean $\Delta t$ duration represents extent of persistent activity in each neuron.

To measure intrinsic neuronal excitability, we used standard procedures to record resting potential, threshold for action potential, rheobase current, and input resistance for each neuron (Barth et al., 2004). To construct an input-output curve, we recorded frontal neurons in the current-clamp mode, and injected various amounts of current through the recording electrode to induce action potentials. Resting membrane potential was set as $-70 \mathrm{mV}$ before current injection. Fifty to four hundred picoamperes of current were injected in $50 \mathrm{pA}$ increments at a fixed duration of $500 \mathrm{~ms}$.

AMPAR-mediated miniature EPSCs (mEPSCs) were recorded at -70 $\mathrm{mV}\left(\mathrm{GABA}_{\mathrm{A}}\right.$ receptor reversal potential) in the presence of TTX $(1 \mu \mathrm{M})$ and bicuculline $(20 \mu \mathrm{M})$ in ACSF. NMDAR-mediated mEPSCs were recorded at $-70 \mathrm{mV}$ with TTX $(1 \mu \mathrm{M})$, CNQX $(20 \mu \mathrm{M})$, and bicuculline (20 $\mu \mathrm{M})$ in magnesium-free ACSF. mEPSCs were analyzed using MiniAnalysis software (Synaptosoft). The miniature events were first automatically detected with a peak amplitude threshold equivalent to $2.5 \mathrm{SDs}$ of baseline noise. Individual events were subsequently inspected and verified by a human observer blind to the experimental conditions of the traces. Data from a 180-s-long recording period were used to determine event frequency and mean amplitude for each cell.

To measure evoked AMPAR-mediated currents, frontal slices were pretreated with cyclothiazide $(100 \mu \mathrm{M})$ to prevent AMPAR desensitization (Stuber et al., 2008), then briefly (30 s) perfused with AMPA (1 $\mu \mathrm{M})$. Neurons were recorded in the voltage-clamp mode at $-70 \mathrm{mV}$ in the presence of TTX $(1 \mu \mathrm{M})$ and bicuculline $(20 \mu \mathrm{M})$ in ACSF. To measure evoked NMDAR-mediated currents, frontal slices were briefly perfused with NMDA $(8 \mu \mathrm{M})$ and SKF38393 $(2 \mu \mathrm{M})$ for $30 \mathrm{~s}$. Neurons were re- 
A

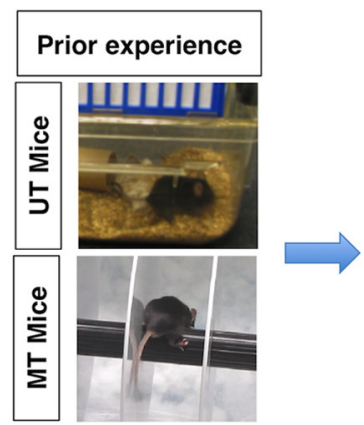

B

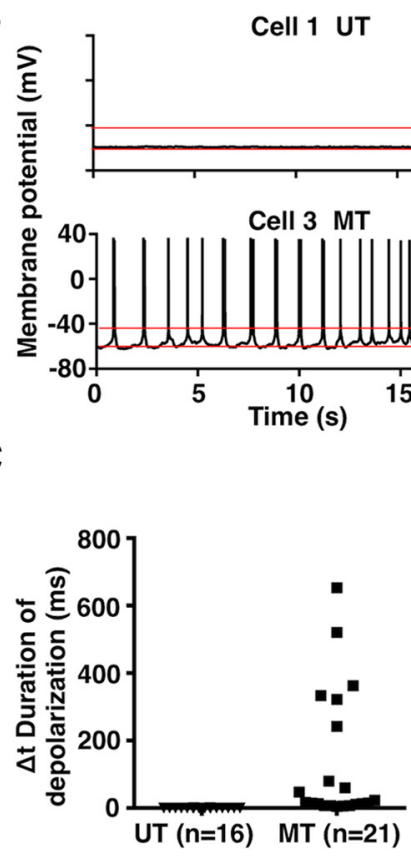

Subsequent slice physiology

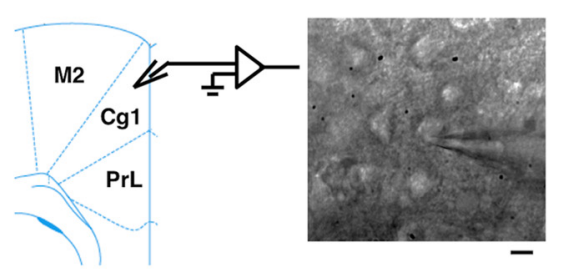

Cell 2 UT

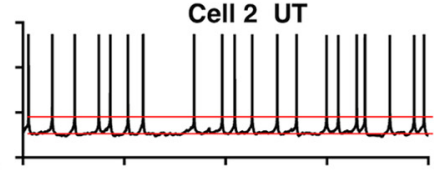

Cell 4 MT

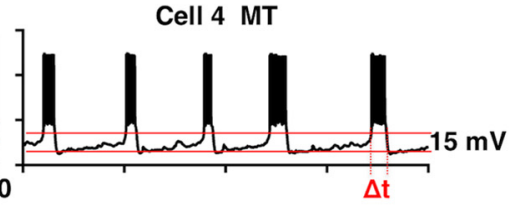

D

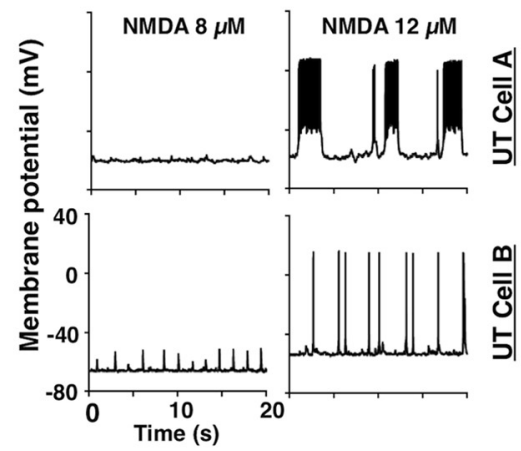

Figure 1. Motor training increases persistent firing in subsets of frontal cortical neurons. $A, A$ schematic diagram of the experimental setup. Before acute brain slice preparation, HET Arc-GFP mice either stayed in their home cages [untrained mice (UT Mice)] or underwent a 45 min motor-training task (MT Mice). Two hours after the beginning of the motor training, acute frontal cortical slices were prepared. Neurons in the superficial layers of the $\mathrm{C} g 1$ area were randomly selected and subjected to whole-cell recording under current-clamp configuration. Scale bar, $10 \mu \mathrm{m}$. $\boldsymbol{B}$, Representative traces of membrane potential were derived from randomly recorded frontal neurons in slices bathed in NMDA $(8 \mu \mathrm{M})$ and D1R agonist SKF38393 $(2 \mu \mathrm{M})$. Slices from UT mice showed only cells with (1) subfiring threshold fluctuation of membrane potentials or (2) single spikes. Slices from MT mice showed only cells with (3) single spikes/shortbursts or (4) persistent firing activity. $\Delta t$ is the time between initial upward crossing and immediate downward crossing of the threshold set at $15 \mathrm{mV}$ above baseline membrane potential. $C$, Mean duration $(\Delta t)$ of each neuron randomly sampled in slices from UT and MT mice (5 mice per group). In slices from UT mice, none of the 16 neurons sampled exhibited persistent activity. In slices from MT mice, 6 of the 21 neurons sampled exhibited persistent activity. $D$, Representative membrane potential traces of two neurons from UT mice, which were exposed to increasing dosage of NMDA in the slice medium. Neither cell showed persistent firing in response to $8 \mu \mathrm{m} \mathrm{NMDA}$ and $2 \mu \mathrm{m}$ SKF38393. When NMDA concentration was raised to $12 \mu \mathrm{m}$, Cell A showed persistent firing, but Cell B did not. Of the six cells tested, three showed persistent firing at higher concentrations of NMDA, suggesting that persistent firing patterns in frontal slices are sensitive to NMDA dosage and different neurons have different sensitivity.

corded in the voltage-clamp mode at $-70 \mathrm{mV}$ in the presence of TTX (1 $\mu \mathrm{M})$, bicuculline $(20 \mu \mathrm{M})$, and CNQX $(20 \mu \mathrm{M})$ in magnesium-free ACSF. Peak amplitude of evoked AMPAR-mediated or NMDAR-mediated currents was determined for each neuron.

For paired-pulse ratio analysis, EPSCs were elicited by paired-pulse stimulation at $50 \mathrm{~ms}$ intervals in the presence of bicuculline $(20 \mu \mathrm{M})$ in ACSF. Electric stimulations (10 times at $0.033 \mathrm{~Hz}$ ) were delivered through a monopolar glass stimulating electrode, which had been placed in layer II/III, $\sim 100 \mu \mathrm{m}$ away from the recorded cell in the same layer. Stimulation intensity was adjusted to evoke EPSC at a range of 200-300 pA. The paired-pulse ratio was measured as EPSC2/EPSC1.

For all of our electrophysiological experiments, we typically recorded 2-4 neurons (including GFP + and GFP- ones) from each mouse, using
4-10 mice from each experimental group. All data analyses were conducted with researchers blind to GFP expression, behavioral condition, or Arc genotype.

Drugs and chemicals. NMDA, AMPA, SKF 38393, CNQX, APV, TTX, bicuculline, and cyclothiazide were obtained from Sigma-Aldrich. MK-801 was purchased from Tocris Bioscience.

Histochemistry. Mice were perfused with $4 \%$ paraformaldehyde in PBS, then coronal slices of $60-100 \mu \mathrm{m}$ were sectioned from the fixed brains. Arc-GFP was excited with $488 \mathrm{~nm}$ laser and detected in the green channel using standard confocal fluorescent microscopy (Olympus; Wang et al., 2006). The excitatory neurons in frontal cortical sections were labeled with mouse monoclonal antibody specific for CaMKII $\alpha$ (at 1:250 dilution; Santa Cruz Biotechnology), and imaged using the standard protocol for immunofluorescent confocal imaging (Wang et al., 2006). The fluorescent images of Arc-GFP were analyzed with NIH Image J and custom-written scripts in Matlab. In fixed brain sections, a computer algorithm analyzing center-surround contrast was used to detect Arc-GFP+ neurons (Wang et al., 2006). In acute slices, visual inspection was used to select GFP+ neurons for electrophysiological recording. The brightness of a recorded neuron was then determined from its confocal image by dividing the mean intensity of the cell soma by the mean intensity of its surrounding area.

Data analysis. The statistical differences among groups of data were determined by ANOVA (one way, two way, or repeated measures) followed by multiple-comparison tests. Data are displayed as mean \pm SE.

\section{Results}

\section{Motor training increases persistent}

firing in subsets of frontal

cortical neurons

To investigate the effects of prior training experience on the firing patterns of frontal cortical neurons, we used a behavioral task that has been shown to activate the rodent frontal cortex robustly (Holschneider et al., 2003; Costa et al., 2004). In this task, mice need to learn a novel sequence of movements to run on an accelerating rotating rod (rotarod) without falling off. HET Arc-GFP mice $(\sim 2$ months old) received $\sim 45 \mathrm{~min}$ of training and were then returned to their home cages. To assess whether this motor-training task would affect persistent firing patterns in individual frontal neurons, we compared neuronal activity in acute frontal slices prepared from motor-trained mice $2 \mathrm{~h}$ after the start of the training with those prepared from age-matched untrained mice that had stayed in their home cages without any training for the entire time (Fig. 1A).

Previous studies have shown that NMDAR and D1R activities are required for persistent neuronal firing in vivo in frontal cortex (Williams and Goldman-Rakic, 1995; Jackson et al., 2004; Wang et al., 2013) and ex vivo in frontal cortical slices (Tseng and O'Donnell, 2005; Stewart and Plenz, 2006; Durstewitz and Ga- 
briel, 2007). In slices, long-range dopaminergic and glutamatergic inputs to frontal cortical neurons are severed. In addition, the tissue is constantly perfused with ACSF, which lacks dopamine and glutamate. NMDA and D1R agonist are therefore added into ACSF to partially mimic the natural environment for frontal neurons and to initiate persistent firing (Seamans and Yang, 2004; Tseng and O'Donnell, 2005; Stewart and Plenz, 2006; Durstewitz and Gabriel, 2007).

Following this protocol, we included NMDA $(8 \mu \mathrm{M})$ and D1R agonist SKF38393 $(2 \mu \mathrm{M})$ in the medium for frontal slices prepared from the untrained and motor-trained mice. To ensure that any electrophysiological differences detected likely related to experience rather than to variations in cell type or among brain regions, we focused our patch-clamp recordings on excitatory neurons located in superficial layers of the Cg1 area of mouse frontal cortex, which is implicated in memory for motor responses (Dalley et al., 2004). In this area, we found that neurons $(n=16)$ randomly sampled from untrained mice fired only single spikes at low frequencies $(1-3 \mathrm{~Hz}, n=3)$ or had membrane potentials beneath the firing threshold $(n=13)$. By contrast, a subset of randomly sampled neurons from motor-trained mice exhibited sustained high-frequency firing, while other motor-trained mouse neurons fired in single spikes or short bursts (Fig. 1B).

In slice physiological studies, persistent neural activity is usually measured by the length of time during which membrane potential is depolarized to $>15 \mathrm{mV}$ above baseline (Tseng and O'Donnell, 2005; Durstewitz and Gabriel, 2007; Haider and McCormick, 2009). Using this definition, we calculated mean depolarization durations for each randomly sampled neuron. While no neurons sampled from untrained mice generated depolarization lasting hundreds of milliseconds, 6 of 21 (29\%) neurons from motor-trained mice had mean depolarization durations of $>200$ ms. The remaining 15 (71\%) motor-trained mouse neurons fired mostly single spikes or short bursts with a mean depolarization duration of $<100 \mathrm{~ms}$ (Fig. 1C).

These findings indicate that prior motor-training experience increases the occurrence of persistent firing patterns in frontal neurons. We further found that in untrained mice, a higher dosage of NMDA in the slice medium eventually evoked persistent firing in some, but not all, neurons (Fig. 1D). In addition to confirming earlier findings of variation in the distribution of persistent firing patterns among frontal neurons (Durstewitz and Gabriel, 2007), our results more importantly suggest that experience (in this case, motor-task training) can modulate frontal cortical neurons' ability to generate persistent firing patterns.

\section{Motor training increases Arc expression in subsets of frontal cortical neurons}

To investigate the molecular mechanisms by which prior training experience affects the persistent firing patterns in individual neurons, we sought to capture the effects of motor training with a molecular "stamp" that would remain detectable in subsequent electrophysiological characterizations. Using our HET Arc-GFP knock-in line (Wang et al., 2006), we examined first whether the expression of GFP driven by the endogenous Arc promoter (ArcGFP) could be induced by the motor-training task in the mouse frontal cortex. We found that the level of Arc-GFP expression in untrained mice was very low, barely detectable above the background autofluorescence level in fixed frontal cortical sections. By contrast, in motor-trained mice, Arc-GFP expression was robust across areas of the frontal cortex, including Cg1 (Fig. 2A). We also found that, once induced by experience, the expression
A
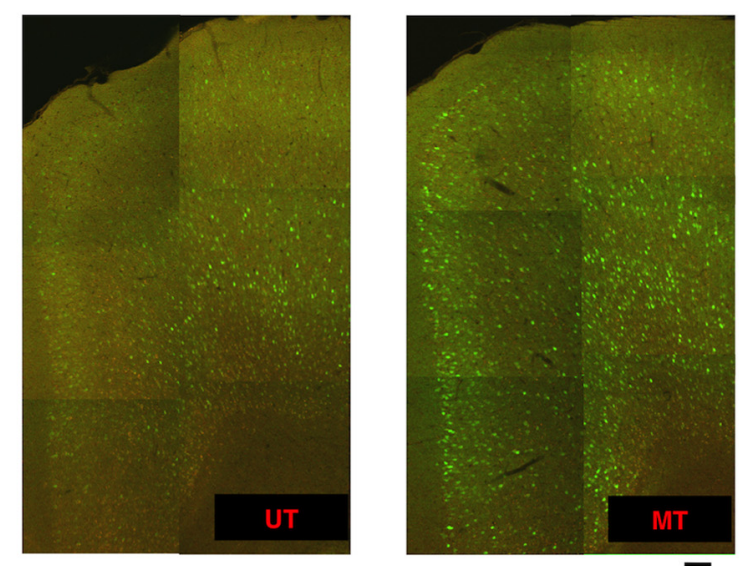

B

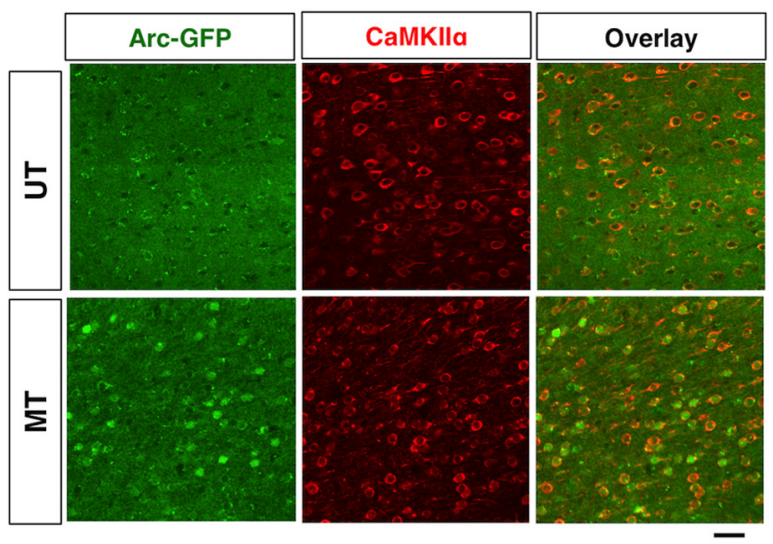

c

After slice cutting

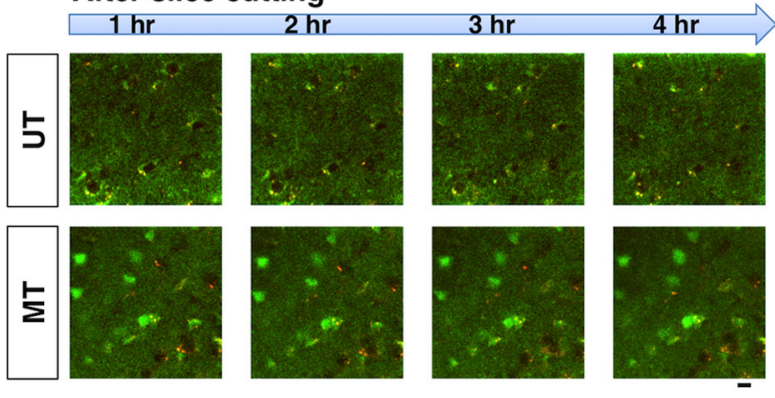

Figure 2. Motor training increases Arc expression in subsets of frontal cortical neurons. $\boldsymbol{A}$, Montage of confocal images shows that motor-training induces Arc-GFP expression in frontal cortex. Arc-GFP expression in untrained (UT) and motor-trained (MT) mice were imaged in fixed frontal sections by confocal microscopy using $488 \mathrm{~nm}$ excitation light and dual (green and red) channel detectors. Arc-GFP fluorescence (green) was detected in the green channel only, whereas tissue autofluorescence was detected in both channels (yellow). Scale bar, $100 \mu \mathrm{m} . \boldsymbol{B}$, Overlap of Arc-GFP-expressing neurons and excitatory neurons in the frontal cortex of UT and MT mice. Arc-GFP + neurons (green) were detected by confocal imaging of green fluorescent signals. Excitatory neurons (red) were labeled by an antibody specific to CaMKII $\alpha$. Scale bar, 30 $\mu \mathrm{m}$. C, Time-lapse imaging of Arc-GFP expression by confocal microscopy in acute live frontal slices after slice preparation. Immediately after slice preparation and over the next $4 \mathrm{~h}$, UTmouse slices show little expression of Arc-GFP (top), suggesting that the process of preparing acute frontal slices does not per se induce new Arc-GFP expression. Across the same four time points, MT-mouse slices exhibit robust and stable Arc-GFP expression with no appearance of new Arc-GFP + neurons (bottom). These results indicate that in acute frontal slices, Arc-GFP expression provides a molecular stamp indicative of prior behavioral experience. Scale bar, $10 \mu \mathrm{m}$.

of Arc-GFP could persist throughout the time required for the preparation and electrophysiological characterization of acute frontal slices (Fig. 2C). These findings suggest that in acute frontal slices, Arc-GFP expression provides a molecular "stamp" indicative of prior behavioral experience. 
A
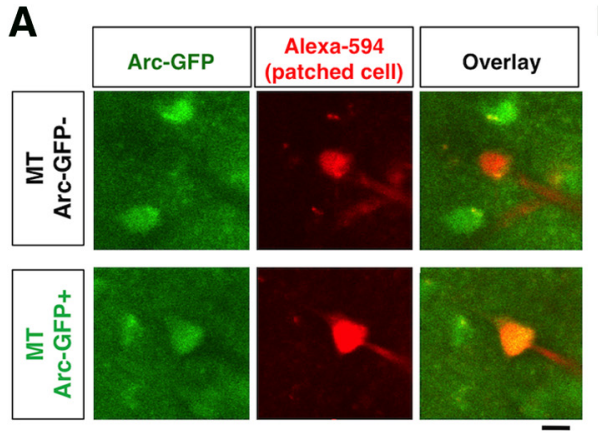

B

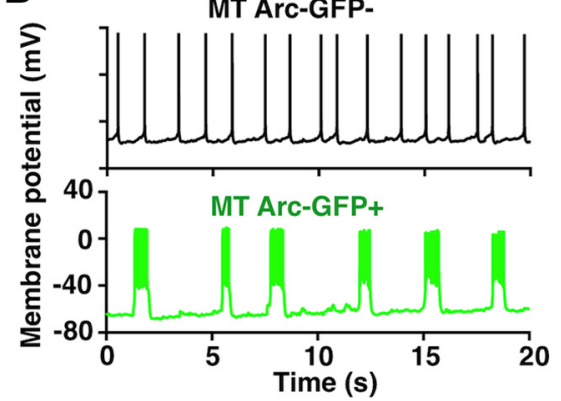

C

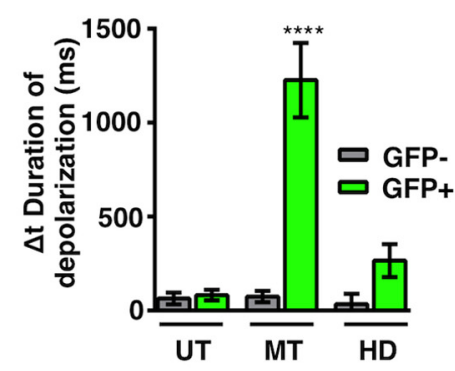

D

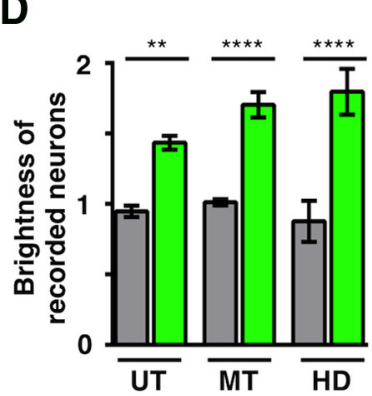

E

$\mathbf{F}$
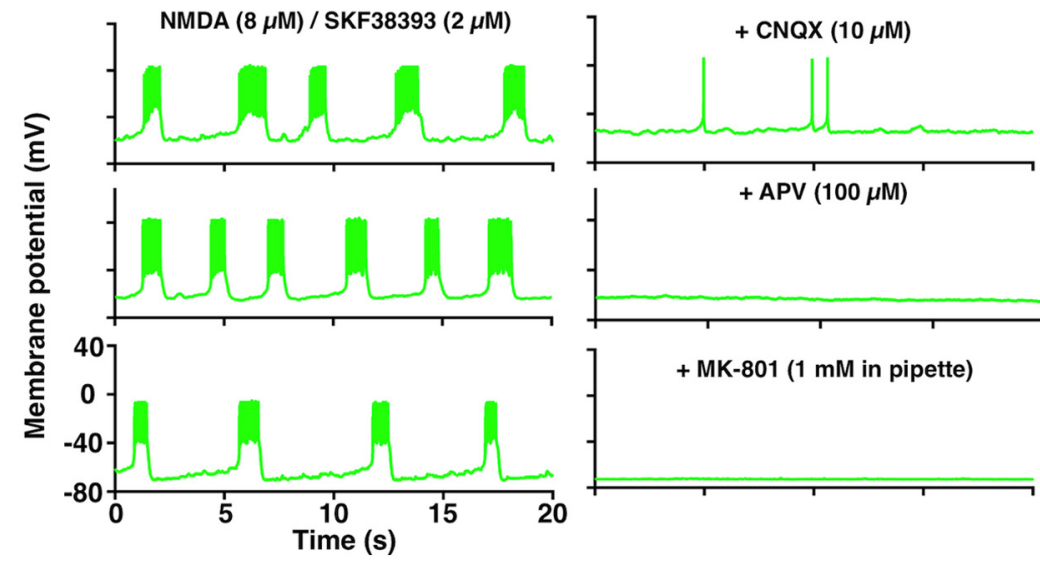

Figure 3. Persistent firing patterns preferentially arise in neurons with motor-training-induced Arc-GFP expression. $\boldsymbol{A}$, Fluorescence-guided patch-clamp of Arc-GFP+ neurons in frontal slices from motor-trained (MT) Arc-GFP HET mice. Arc-GFP + neurons were detected in the green channel of confocal microscopy. Patch-clamp recorded neurons were labeled by a red fluorescent dye (Alexa 594) via recording pipettes. Scale bar, $10 \mu \mathrm{m}$. $\boldsymbol{B}$, Membrane potential traces of Arc-GFP + and Arc-GFP - neurons in frontal slices that were prepared from MT mice and bathed in NMDA $(8 \mu \mathrm{M})$ and SKF38393 $(2 \mu \mathrm{M})$. C, Mean duration of depolarization in Arc-GFP + and Arc-GFP - neurons from untrained (UT, 8 mice), MT (10 mice), and handled (HD, 7 mice) animals. The type of prior experience and the activation history of individual neurons (as reflected by Arc-GFP expression) jointly regulate persistent firing patterns (2-way ANOVA, experience-cell-type interaction, $\left.F_{(2,64)}=14.38, p<0.0001\right)$. The mean duration of depolarization in the Arc-GFP+ neurons from MT mice is significantly longer than in any other group. Neuron numbers: UT GFP - , 8; UT GFP + , 12; MT GFP- , 11; MT GFP + , 15; HD GFP- 11; HD GFP + 12. D, Brightness of recorded neurons. Mean intensity of targeted cell soma was divided by the mean intensity of its surrounding area to derive the brightness index. A ratio $\sim 1$ suggests an Arc-GFP - neuron. Under all behavioral conditions, the brightness of visually identified Arc-GFP + neurons is significantly higher than that of ArcGFP - neurons. Two-way ANOVA, Arc-GFP effect, $F_{(1,62)}=97.53, p<0.0001$. $\boldsymbol{E}$, The percentage of excitatory neurons expressing Arc-GFP in the superficial layers of the $\mathrm{Cg} 1$ area of the frontal cortex in UT, MT, and HD mice. One-way ANOVA, $F_{(2,15)}=34.05, p<0.0001, n=6$ mice per group. $F$, Representative membrane potential traces of Arc-GFP + neurons from MT Arc-GFP HET mice. Persistent firing occurred in the presence of NMDA $(8 \mu \mathrm{M})$ and SKF38393 $(2 \mu \mathrm{M})$, but was blocked by the subsequent addition of AMPAR antagonist CNQX (10 $\mu \mathrm{m}$; top) or NMDAR antagonist APV (100 $\mu \mathrm{m}$; middle) in the bath medium. Five of five neurons tested were blocked with CNQX, and three of three were blocked with APV. Persistent firing was also blocked by intracellular application of NMDAR antagonist MK-801 (1 mm in pipette). Seven of seven neurons (from 4 mice) tested for MK-801 showed no persistent activity (bottom right), while four of four neurons tested without MK-801 (1 from each mouse) showed normal persistent activity (bottom left). All the data are mean $\pm \mathrm{SE}$. Post-tests, ${ }^{*} p<0.05,{ }^{* *} p<0.01,{ }^{* * *} p<0.001,{ }^{* * * *} p<0.0001$.
While a previous study has shown that almost all excitatory cortical neurons are capable of expressing Arc in response to maximal electrical stimulation (Vazdarjanova et al., 2006), our study shows that in mice performing the motor-training task, only a subset of frontal cortical neurons express Arc-GFP. To quantify the percentage of excitatory neurons expressing Arc-GFP, we compared Arc-GFP+ neurons with those expressing calcium/ calmodulin-dependent protein kinase $\alpha$ $(\mathrm{CaMKII} \alpha)$, a maker for all excitatory neurons. In motor-trained mice, $\sim 36 \%$ of the CaMKII $\alpha+$ neurons in the superficial layers of the Cg1 region of the frontal cortex expressed Arc-GFP. By contrast, in untrained mice, only $\sim 3 \%$ CaMKII $\alpha+$ neurons in this area expressed Arc-GFP (Figs. $2 B, 3 E ; p<0.0001$, $t$ test, $n=6$ mice in each group), suggesting that the motortraining task induced Arc-GFP expression in approximately a third of Cg1 neurons.

Persistent firing patterns preferentially arise in neurons with motor-traininginduced Arc-GFP expression

Our earlier findings showed that after the motor-training experience, approximately a third of Cg1 neurons generated persistent activity (Fig. $1 C$ ), similar to the proportion in which Arc-GFP expression was induced. To examine whether persistent firing patterns would preferentially arise in neurons with motor-traininginduced expression of Arc-GFP, we performed fluorescence-guided patch-clamp recording in frontal slices from the motor-trained mice (Fig. $3 A$ ). We found that the mean duration of depolarization in Arc-GFP + neurons $(1227 \pm 198 \mathrm{~ms}$, $n=15)$ was significantly longer than that in Arc-GFP- neurons (75 $\pm 30 \mathrm{~ms}, n=$ 11 ; Fig. $3 B, C)$. This result suggests that the subset of neurons with motor-traininginduced Arc-GFP expression better supports persistent activity compared with Arc-GFP - neurons.

In untrained mice, by contrast, neither Arc-GFP+ nor Arc-GFP- neurons showed persistent firing (Fig. 3C). To assess whether any type of new behavioral experience would increase persistent firing in frontal neurons, we placed a different group of mice on a stationary rotarod, then pulled them off to mimic the new environmental exposure and handling conditions mice encountered in our original motor-training task. In frontal slices taken from these handled mice, the mean duration of depolarization in the Arc$\mathrm{GFP}+$ neurons was slightly longer than that in Arc-GFP - neurons, but signifi- 
cantly shorter than that in the Arc-GFP+ neurons from the motor-trained mice (Fig. 3C, two-way ANOVA, experiencecell-type interaction, $F_{(2,64)}=14.38, p<$ 0.0001 ; post-tests, handled GFP+ vs handled GFP - , $p>0.9999$; handled GFP + vs motor-trained GFP,$+ p<0.0001)$. These results suggested that the type of prior experience and the activation history of individual neurons (indicated by Arc-GFP expression) jointly regulate the emergence of persistent firing patterns in frontal neurons.

Several factors could potentially contribute to the selective occurrence of persistent firing patterns in neurons with motor-training-induced Arc-GFP expression. While the level of Arc-GFP expression may account for the distribution of persistent activity between Arc-GFP+ and Arc-GFP - neurons in motor-trained mice, it does not explain differences in the firing patterns of Arc-GFP+ neurons from different experience groups (Fig. $3 C, D)$. Alternatively, the number of Arc$\mathrm{GFP}+$ neurons in the local circuit (Fig. $3 E$ ) and the level of Arc-GFP expression within each neuron may together predict the extent of persistent activity. Persistent neuronal firing in frontal slices depends on inputs from local network activity, as antagonists of AMPA-type or NMDAtype glutamate receptors block synaptic transmission and stop persistent firing (Tseng and O'Donnell, 2005; Durstewitz and Gabriel, 2007; Fig. 3F). In motor-trained mice, the higher number of Arc-GFP + neurons with their highfrequency firing outputs may provide stronger local excitatory feedback that ensures persistent firing. While such network mechanisms may facilitate persistent firing, we also found that intracellular application of NMDAR antagonist MK-801 is sufficient to prevent persistent firing. This result suggests that at the single-cell level, NMDAR activation is required to generate persistent activity (Fig. 3F). Motor-training experience, therefore, may induce changes in individual Arc-GFP-expressing neurons to promote persistent firing patterns.

\section{Arc is functionally required for motor-training-induced persistent firing patterns}

Seeking the molecular mechanisms involved in the regulation of persistent firing patterns in Arc-GFP + neurons from motortrained mice, we conducted tests first to see whether the Arc gene is functionally required for this process. Experiments using the water maze task had earlier shown that deletion of the Arc gene in mice affects long-term memory consolidation, but not shortterm learning (Plath et al., 2006; Peebles et al., 2010). Using the accelerating rotarod task, we observed that, at the end of a $45 \mathrm{~min}$ motor-training session, all mice achieved similar rotation speeds before falling, regardless of genotypes (WT, with two complete copies of Arc; HET, with only one copy of Arc replaced by GFP; HOM, with both copies replaced by GFP; one-way ANOVA, $F_{(2,55)}=0.74, p=0.48$; Figure $\left.4 A\right)$. Initially, therefore, the presence or absence of Arc made no difference to performance. On the following $2 \mathrm{~d}$, however, both WT and HET mice improved ${ }^{*} p=0.0127$.
B

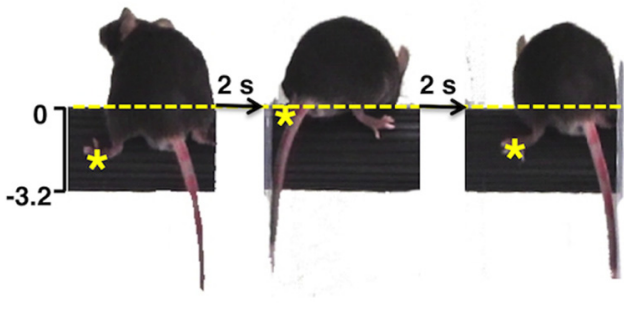

D

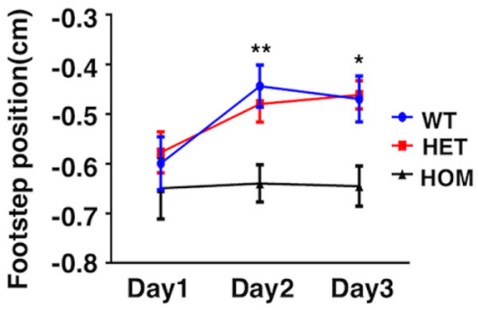

Figure 4. Arc function is important for the long-term improvement of motor strategy in the rotarod task. $\boldsymbol{A}$, Rotarod perfor0.0439. WT, 9 mice; HET, 12 mice; HOM, 11 mice. Data are mean \pm SE. Post-tests, WT versus HOM: Day $2,{ }^{* *} p=0.0049 ;$ Day 3 ,

their running strategies by placing their footsteps closer to the top of the rotarod, while the HOM mice, which lack the Arc gene, did not (Fig. 4B-D). These results confirm an important role of Arc in the consolidation of information learned from experience.

To assess the impact of Arc deletion on frontal persistent activity generated after a comparable level of motor training, we randomly sampled neurons in frontal slices prepared from WT and HOM mice after a single training session. We found that the distribution of depolarization duration in neurons from the WT mice (Fig. 5A) was similar to that in the HET mice (Fig. $1 C$ ), with $\sim 30 \%$ of the neurons sampled having a mean duration of depolarization in the hundreds-of-milliseconds range. By contrast, firing activity in all 21 neurons sampled from HOM mice clustered below the low hundreds-of-milliseconds range (Fig. 5A). The diminished persistent firing in HOM mice suggests that the Arc protein is required for motor-training-induced persistent firing patterns.

To ascertain whether this diminished persistent activity in HOM mice was due to the motor-training task failing to activate the endogenous $A r c$ promoter (as represented by the expression of Arc-GFP), or to lack of Arc protein expression (Wang et al., 2006), we next quantified Arc-GFP expression levels in HOM mice. Approximately 38\% of the frontal excitatory neurons robustly expressed Arc-GFP as induced by the motor-training task in the HOM mice (Fig. 5B). Thus, the motor-training experience indeed activated the endogenous Arc promoter in the HOM mice to a similar extent as in the HET mice, suggesting that Arc protein itself is not necessary for the activation of $A r c$ promoter. Together with the above electrophysiological findings (Fig. 5A), these results suggest that the circuitry is in place to initiate training- 


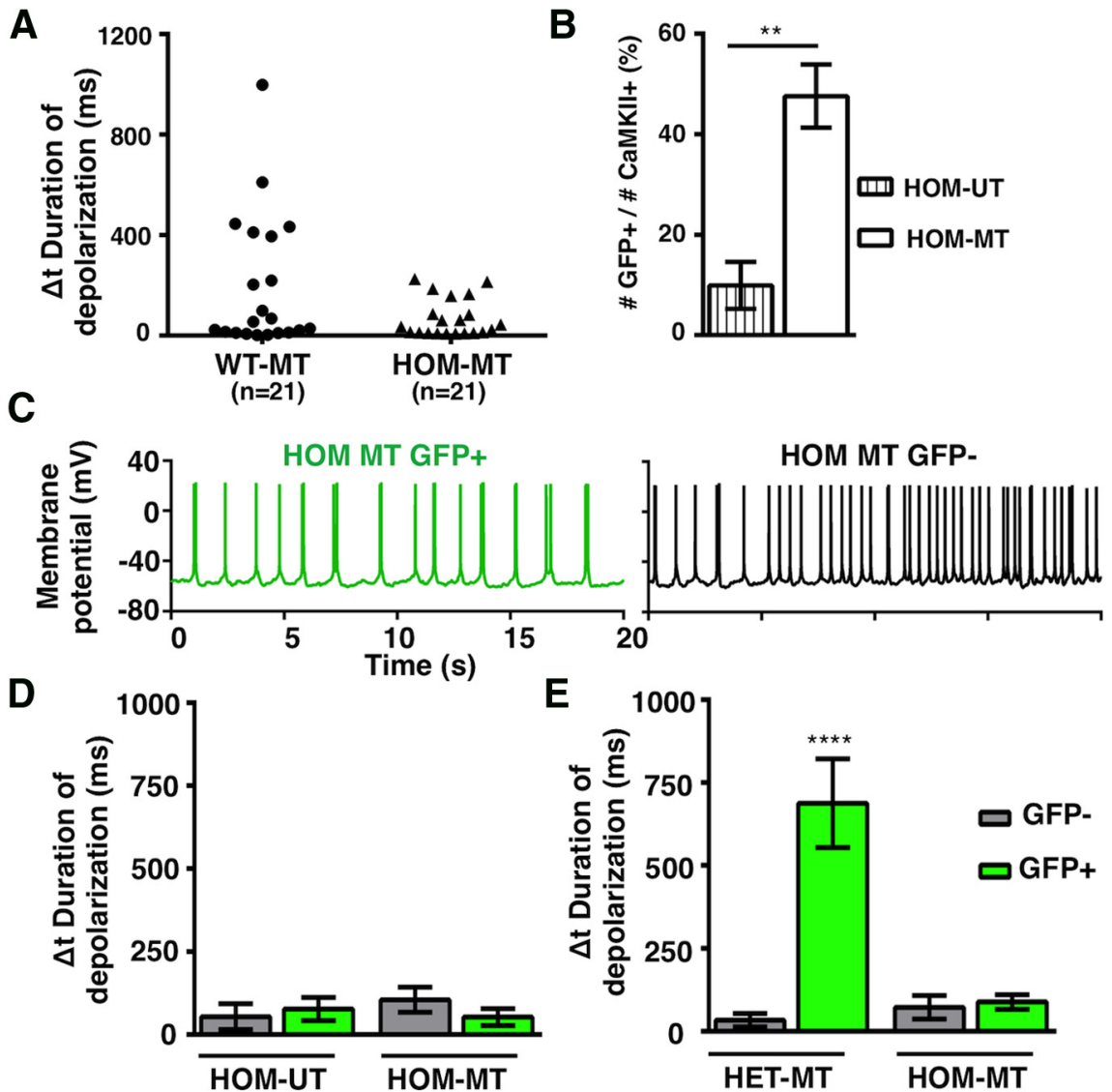

Figure 5. Arc is functionally required for motor-training-induced persistent firing patterns. $\boldsymbol{A}$, Mean duration $(\Delta t)$ of depolarization for each neuron randomly sampled, regardless of their GFP expression, in frontal slices prepared from the motor-trained (MT) Arc WT and HOM mice (5 mice per group). $\boldsymbol{B}$, The percentage of excitatory neurons expressing GFP in frontal cortex is lower in the untrained (UT) compared with the MT HOM mice ( $t$ test; UT, 5 mice; MT, 6 mice). C, Membrane potential traces of GFP + and GFP - neurons in frontal slices that were prepared from HOM MT mice and bathed in NMDA (8 $\mu \mathrm{M})$ and SKF38393 $(2 \mu \mathrm{M})$. D, Mean depolarization duration in GFP + and GFP - neurons from UT (6 mice) and MT (8 mice) HOM animals. No significant group difference. One-way ANOVA, $F_{(3,35)}=0.5051, p=0.6812$. Neuron numbers: UT GFP - , 9; UTGFP +, 10; MTGFP - , 10; MT GFP +, 10. $\boldsymbol{E}$, Mean depolarization duration in GFP + and GFP - neurons from HET (9 mice) and HOM (10 mice) MT animals. The mean depolarization duration in the GFP + neurons from HET MT mice was significantly longer than any other groups. Two-way ANOVA, genotype-cell-type interaction, $F_{(1,48)}=29.47, p<0.0001$. Neuron numbers: HET MT GFP - , 14; HET MT GFP +, 11; HOM MT GFP- $14 ;$, HOM MT GFP,+ 13 . All the data are mean \pm SE. Post-tests, ${ }^{* *} p<0.01,{ }^{* * *} p<0.0001$

dependent gene expression, but not to facilitate persistent activity in those neurons from the HOM mice.

The induction of GFP in the HOM mice further allowed us to compare the firing patterns of behaviorally activated neurons $(\mathrm{GFP}+)$ with the rest of neurons $(\mathrm{GFP}-)$ in the absence of Arc protein. We first measured the mean duration of depolarization in frontal neurons from both motor-trained and untrained HOM mice. The results showed that in the HOM mice, neither GFP+ nor GFP - neurons exhibited persistent firing; moreover, motortraining experience failed to increase persistent firing (Fig. $5 C, D$; one-way ANOVA, $\left.F_{(3,35)}=0.5051, p=0.6812\right)$. To further confirm our observation that persistent firing depends on the Arc gene, we next subjected a new cohort of HET and HOM mice, blindly assigned to the experimenter, to motor training and recorded their neuronal activity afterward. We found that GFP+ neurons in the HOM mice showed a significantly shorter duration of depolarization than those in the HET mice (Fig. 5E; twoway ANOVA, genotype-cell-type interaction, $F_{(1,48)}=29.47$, $p<0.0001$. Post-test, HET motor-trained GFP + vs HOM motor-trained GFP,$+ p<0.0001)$. These results suggest that the expression of Arc protein is necessary for the emergence of persistent firing patterns in motor-training-activated neurons.

Arc expression does not affect the intrinsic membrane excitability of frontal neurons

Having demonstrated Arc protein's essential role in the persistence of neuronal firing patterns, we next sought to determine the molecular mechanisms underlying this effect. Previous studies have suggested that persistent activity depends on the interplay between intrinsic membrane excitability and synaptic activity (Wang, 2001; Major and Tank, 2004; Haider and McCormick, 2009). We therefore began by characterizing intrinsic membrane excitability levels in GFP+ and GFP - neurons prepared from motortrained HET and HOM mice. All four groups of neurons showed no significant differences in resting membrane potential, threshold membrane potential, input resistance, or rheobase current (Table 1), suggesting that the presence or absence of the Arc protein has no discernable effect on the basic membrane properties of frontal neurons.

To further assess potential differences in excitability between neuronal groups, we next injected various amounts of current $(50-400 \mathrm{pA})$ into a neuron and measured the number of spikes evoked. Using these data, we constructed a neuronal input-output curve (Fig. 6A). As with the passive membrane properties, we found no significant differences in the inputoutput relationship among the four neuronal groups (Fig. 6B), suggesting that Arc protein does not affect intrinsic membrane excitability in frontal neurons. Given these results, it appears unlikely that Arc regulates persistent firing patterns by modulating membrane excitability.

\section{Arc's effects on AMPAR function do not correlate with changes in persistent firing patterns}

To examine the effects of Arc on synaptic activity and determine whether they are correlated with persistent firing patterns, we first assessed AMPAR-mediated functions in GFP+ and GFPfrontal neurons sampled from motor-trained HET or HOM mice (Fig. 7A). Our findings showed that the frequency (not mean amplitude) of AMPAR-mediated mEPSCs were different among the four groups of neurons (Fig. 7B,C). Differences in mEPSC frequency between neurons may reflect presynaptic differences, such as transmitter release probability, or postsynaptic differences, such as number of synapses containing detectable amounts of AMPARs (Luscher and Malenka, 2012). To assess whether presynaptic release differed between the four groups of neurons, we compared their responses to paired-pulse stimulation. The stimulating electrode was placed in layer II/III, $\sim 100 \mu \mathrm{m}$ away from the recorded neuron in the same layer. While the exact 
Table 1. Intrinsic membrane properties of neurons from motor-trained mice

\begin{tabular}{lcccc}
\hline & $\begin{array}{l}\text { HET motor- } \\
\text { trained GFP }-\end{array}$ & $\begin{array}{l}\text { HET motor- } \\
\text { trained GFP }+\end{array}$ & $\begin{array}{l}\text { HOM motor- } \\
\text { trained GFP }-\end{array}$ & $\begin{array}{l}\text { HOM motor- } \\
\text { trained GFP }+\end{array}$ \\
\hline Resting potential (mV) & $-65.6 \pm 0.6$ & $-65.86 \pm 0.6$ & $-67.0 \pm 0.5$ & $-66.8 \pm 0.6$ \\
$\begin{array}{l}\text { Threshold for action } \\
\quad \text { potential (mV) }\end{array}$ & $-43.5 \pm 0.4$ & $-41.4 \pm 0.8$ & $-42.3 \pm 0.8$ & $-44.0 \pm 0.8$ \\
Input resistance (M $\Omega)$ & $167.5 \pm 11.9$ & $178.3 \pm 15.2$ & $166.6 \pm 10.8$ & $170.4 \pm 12.2$ \\
Rheobase current (pA) & $129 \pm 12.8$ & $135.5 \pm 10.1$ & $145 \pm 13.1$ & $127 \pm 12.0$ \\
Cell number & 10 & 12 & 10 & 10 \\
\hline
\end{tabular}

The intrinsic membrane properties of GFP + and GFP - neurons from Arc HET (6 mice) or HOM (6 mice) motortrained animals were comparable among groups. One-way ANOVA, resting potential: $F_{(3,38)}=1.421, p=0.2516$; threshold for action potential : $F_{(3,38)}=1.855, p=0.1538$; input resistance: $F_{(3,38)}=0.01536, p=0.9974$; rheobase current: $F_{(3,38)}=0.4443, p=0.7227$.

synaptic pathways recruited are not known due to the technical limitation of electrical field stimulation, this electrode placement likely activates recurrent intracortical inputs to the recorded neuron. Using this method, we found no difference in paired-pulse ratio, suggesting that presynaptic release probability is comparable for the four neuronal groups (Fig. $7 D, E$ ).

To assess whether the neurons from the four groups differ in terms of postsynaptic AMPAR function, we next conducted whole-cell voltage-clamp recording of evoked AMPAR current by briefly perfusing AMPA ( $1 \mu \mathrm{M}$ for $30 \mathrm{~s}$ ) into the recording chamber while blocking other synaptic currents and action potentials pharmacologically (Fig. $7 F$ ). Our findings showed that the amplitude of evoked AMPAR current is affected jointly by Arc genotype and cellular activation history (Fig. 7G, two-way ANOVA, genotype-cell-type interaction, $F_{(1,53)}=9.901, p=$ $0.0027)$. While the pattern of difference in evoked AMPAR current is consistent with that in mEPSC frequency (Fig. $7 B$ ), it does not correlate with that in persistent firing (Fig. 5E). Therefore, AMPAR modulation is unlikely to account for Arc-dependent regulation of persistent firing patterns.

\section{Arc-dependent enhancement of NMDAR function correlates with persistent firing patterns}

Next, we examined NMDAR-mediated function in GFP + and GFP - frontal neurons from motor-trained HET and HOM mice. Detecting NMDAR-mediated mEPSCs in slices is difficult because of the increased "noise" generated by opening of NMDARs at the ambient glutamate level and the slow time course of NMDAR events (Sah et al., 1989). Nevertheless, in our slice preparation, large NMDAR events were clearly present (Fig. $8 A$ ). Those events were detected by using a peak amplitude threshold equivalent to 2.5 SDs of baseline noise. We found that the frequency (not mean amplitude) of those detected NMDAR events increased significantly in GFP + neurons from motortrained HET mice, whereas the other three groups remained at similar levels (two-way ANOVA, genotype-cell-type interaction, $F_{(1,35)}=21.44, p<0.0001$; Fig. $\left.8 B, C\right)$.

To determine whether the evoked NMDAR current is similarly enhanced in HET motor-trained GFP + neurons, we conducted whole-cell voltage-clamp recording in the presence of bath-applied NMDA (Stuber et al., 2008; Suh et al., 2010). We did not use afferent stimulation to compare evoked NMDAR current, because it would be difficult to standardize the amount of stimulation received by neurons from different slices. We evoked NMDAR current by briefly perfusing NMDA $(8 \mu \mathrm{M})$ and SKF38393 $(2 \mu \mathrm{M})$ for $30 \mathrm{~s}$ into the recording chamber while blocking non-NMDA synaptic currents and action potentials pharmacologically (Fig. 8D). Our findings showed that the peak amplitude of evoked NMDAR current was significantly larger in
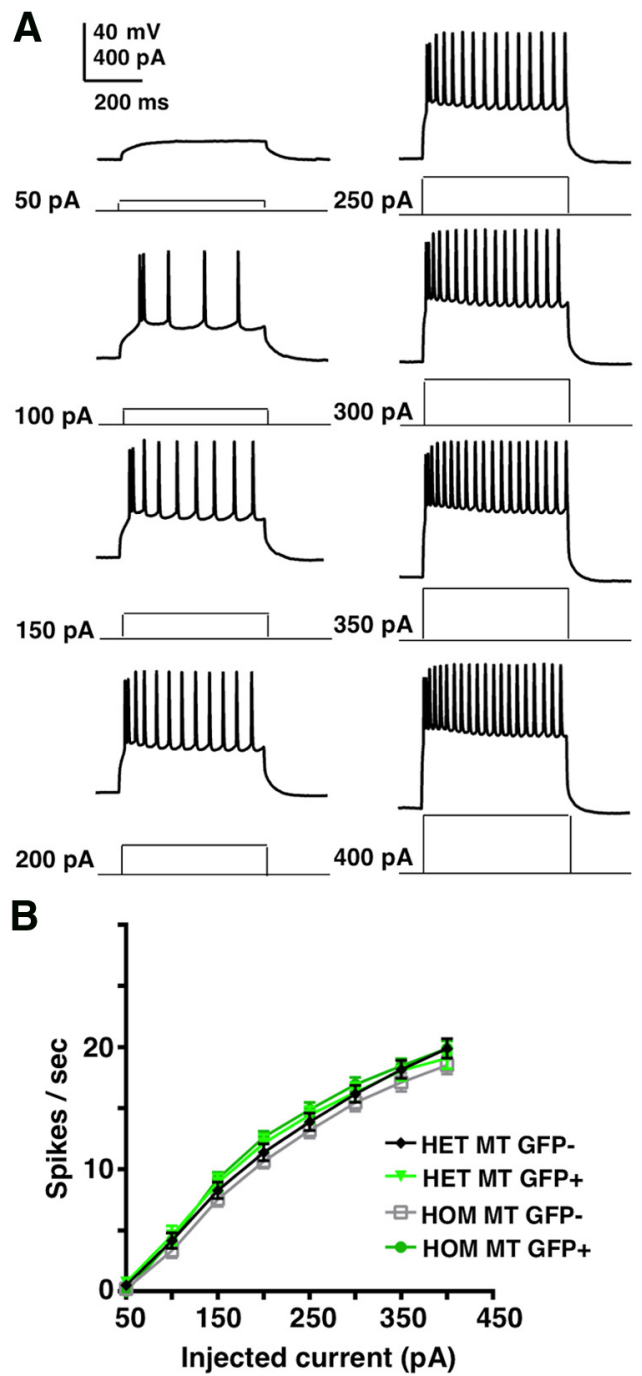

Figure 6. Arc expression does not affect the intrinsic membrane excitability of frontal neurons. $\boldsymbol{A}$, Representative traces of action potentials evoked by various amounts of current injected through the recording pipette into a neuron. $\boldsymbol{B}$, Input- output curve of injected currents versus number of spikes. GFP + and GFP - neurons from HET (8 mice) and HOM (7 mice) motor-trained (MT) mice were recorded in the current-clamp mode, and action potentials were induced by current injection (500 ms). No significant difference in input- output relationship among the four groups. Two-way repeated-measures ANOVA: group effect, $F_{(3,67)}=0.8792$ $p=0.4564$; current- group interaction effect, $F_{(21,469)}=1.114, p=0.329$. HET MT GFP -, 18 neurons; HET MT GFP + , 20 neurons; HOM MT GFP - , 15 neurons; HOM MT GFP + , 18 neurons.

HET motor-trained GFP + neurons than in any of the other three neuronal groups (Fig. 8E; two-way ANOVA, genotype-cell-type interaction, $\left.F_{(1,62)}=13.93, p=0.0004\right)$. While bath application of NMDA does not distinguish synaptic from extrasynaptic NMDARs, the observed pattern of difference among the four neuronal groups is consistent with that in NMDA mEPSC frequency, which suggests a change at the synaptic level (Fig. $8 B$ ). Together, these findings demonstrate that enhanced NMDAR function in GFP+ neurons activated by prior motor-training experience requires Arc. Increased NMDAR function occurs only in HET motor-trained GFP + neurons, in which persistent firing is observed (Fig. $5 E$ ), further suggesting that NMDAR function level may regulate how persistent firing patterns arise in different frontal neurons in motor-trained mice.

Noting that frontal neurons from untrained mice show little evidence of persistent firing patterns regardless of Arc expression 
A

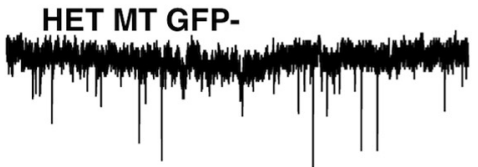

HET MT GFP

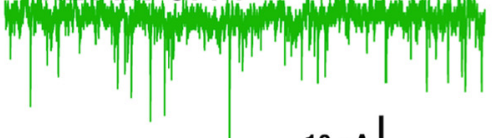

$10 \mathrm{pA}$

HOM MT GFP.

$1 \mathrm{~s}$

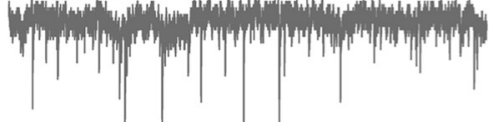

HOM MT GFP+

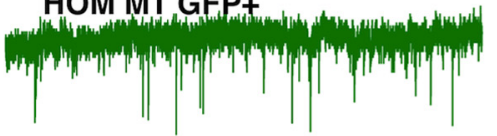

$\mathbf{D}$

HET MT GFP. $\quad$ HET MT GFP+

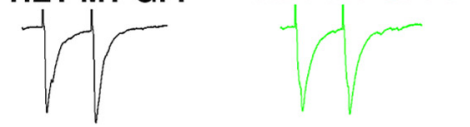

HOM MT GFP. HOM MT GFP+<smiles>CCC1CCC(C)C(C)C1C</smiles>

$F$

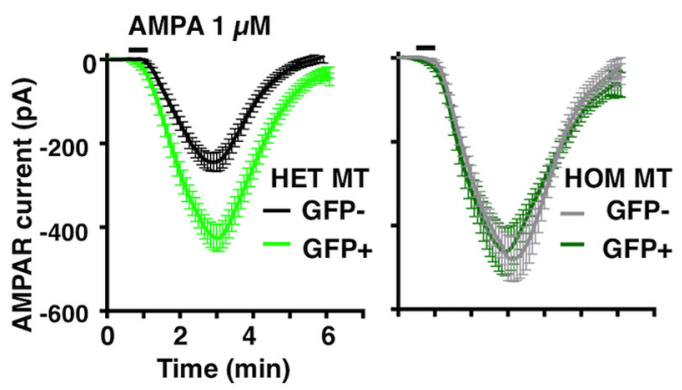

B

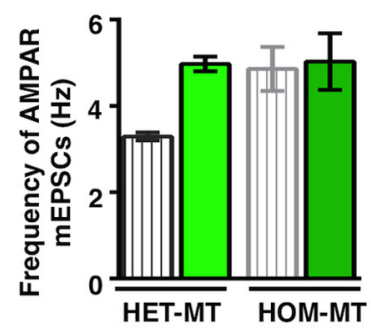

C

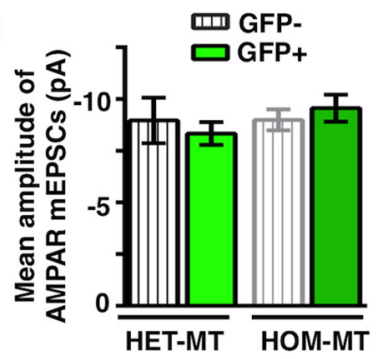

$\mathbf{E}$

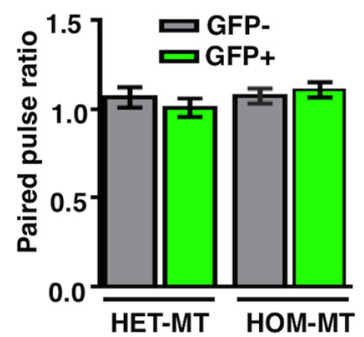

$\mathbf{G}$

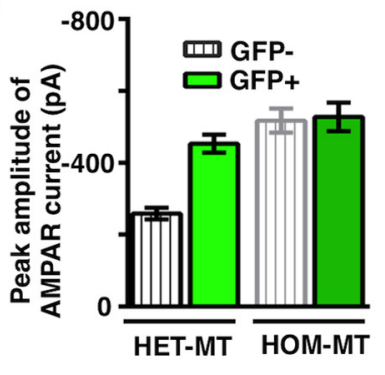

Figure 7. Arc's effect on AMPAR function does not correlate with changes in persistent firing patterns. A, AMPAR-mediated mEPSC traces in GFP + and GFP - neurons from HET (5 mice) and HOM (5 mice) motor-trained (MT) animals. Miniature AMPAR currents were recorded at a holding potential of $-70 \mathrm{mV}$ with TTX $(1 \mu \mathrm{M})$ and bicuculline $(20 \mu \mathrm{M})$ in normal ACSF. B, C, The frequency $(\boldsymbol{B})$, but not mean amplitude $(\boldsymbol{C})$, of AMPAR-mediated mEPSCs was different among the four groups of neurons. One-way ANOVA: frequency, $F_{(3,27)}=3.330, p=0.0343$; amplitude, $F_{(3,27)}=0.5120, p=0.6774$. Neuron numbers: HET GFP-, 7; HET GFP + , 8; HOM GFP- , 8; HOM GFP + , 8. D, Representative traces of EPSCs evoked by paired-pulse extracellular synaptic stimulation at $50 \mathrm{~ms}$ interval. Paired-pulse ratio, EPSC2/EPSC1. E, Average of the paired pulse ratio in GFP + and GFP - neurons from HET (4 mice) and HOM (5 mice) MT animals. Lack of Arc does not affect presynaptic release properties. One-way ANOVA, $F_{(3,29)}$ $=0.7380, p=0.5380$. Neuron numbers: HET GFP - , ; HET GFP + , 8; HOM GFP - , 8; HOM GFP + , 9.F, AMPAR-mediated current evoked by a brief perfusion ( $30 \mathrm{~s}$; black bar) of AMPA $(1 \mu \mathrm{M})$ into frontal slices. Slices were pretreated with cyclothiazide $(100 \mu \mathrm{M})$ to prevent AMPAR desensitization. Neurons were recorded in the voltage-clamp mode at $-70 \mathrm{mV}$ in the presence of TTX (1 $\mu \mathrm{M})$ and bicuculline $(20 \mu \mathrm{m})$ in ACSF. Each trace is averaged from all the neurons in each experimental group. G, Quantification of the peak amplitude of evoked AMPAR currents in GFP + and GFP - neurons from HET (5 mice) and HOM (5 mice) MT animals shows that AMPAR current is affected jointly by Arc genotype and cellular activation history. Two-way ANOVA, genotype-cell-type interaction, $F_{(1,53)}=9.901, p=0.0027$. Neuron numbers: HET GFP - , 15; HET GFP,+ 15 ; HOM GFP,$- 14 ;$ HOM GFP + , 13. All the data are mean $\pm \mathrm{SE}$.

(Figs. 3C, 5D), we next compared the distribution of NMDAR current in GFP + and GFP - frontal neurons prepared from untrained HET and HOM mice. Using the same method as described above to measure evoked NMDAR current, we found comparable peak amplitudes of NMDAR current between GFP+ and GFP - neurons from untrained HET or HOM mice (Fig. $9 D, E)$. Moreover, those amplitudes from untrained mice were at least threefold lower than those observed in GFP + neurons from motor-trained HET mice (Fig. 8D,E). These findings confirm that level of NMDAR function associates with the distribution of persistent firing patterns in frontal neurons.

In untrained HOM mice, the average level of evoked NMDAR current was lower than that in untrained HET mice (Fig. 9D,E; two-way ANOVA, genotype effect, $\left.F_{(1,38)}=6.054, p=0.0185\right)$. While this difference $(\sim 60 \mathrm{pA})$ is not as large as that between the GFP + neurons from motor-trained HET and HOM mice $(\sim 250$ pA; Fig. $8 E)$, it shows that the germ-line knock-out of $A r c$, which results in the lack of Arc protein throughout life, does affect baseline NMDAR function. By contrast, the lack of Arc does not affect intrinsic membrane excitability or AMPAR function in untrained mice (Table 2; Fig. 9A-C), suggesting that Arc protein in frontal neurons may selectively affect NMDAR function.

Together, our findings show that in frontal neurons activated by motortraining experience, Arc is required for the selective enhancement of NMDAR function. Furthermore, level of NMDAR function, as modulated by Arc, correlates with the distribution of persistent firing patterns among frontal neurons. Since NMDAR function controls persistent firing bidirectionally (Figs. $1 D, 3 F$ ), modulation of NMDAR function may be the mechanism by which Arc regulates the experienceinduced persistent firing patterns in frontal neurons.

\section{Discussion}

Persistent neural activity has been observed in many different brain regions and is considered a key neurophysiological substrate for information retention (Fuster, 2001; Miller and Cohen, 2001; Wang, 2001; Major and Tank, 2004). While previous research has recognized the influence of prior training experience on the emergence of persistent activity in specific neuronal populations (Fuster, 1973; Takehara-Nishiuchi and McNaughton, 2008; Histed et al., 2009; Erlich et al., 2011), the molecular pathways involved in regulating these persistent firing patterns following a training experience have yet to be elucidated. To demonstrate that motor-task training does indeed increase persistent activity in subsets of frontal cortical neurons, we subjected mice to behavioral training and examined subsequent physiological events in acute ex vivo slices of their frontal cortex. By imaging a genetically encoded fluorescent reporter under the control of the endogenous Arc promoter, we found that motortraining experience induces Arc expression in subsets of frontal cortical neurons, which prepares those neurons for persistent 
firing in response to subsequent circuit activation. By contrast, in Arc gene knockout mice, which lack Arc protein, although the circuitry is still in place to initiate training-dependent gene expression, it failed to facilitate persistent neural activity. These findings therefore implicate Arc as a key molecular link between prior experience and the establishment of persistent firing patterns in select frontal cortical neurons.

While earlier studies suggest that both single-cell and network mechanisms can contribute to the generation of persistent activity in the brain, little is as yet known about the ways in which prior experience affects those mechanisms (Wang, 2001; Major and Tank, 2004; Haider and McCormick, 2009). Intrinsic cellular mechanisms contribute to persistent activity through slow currents conducted by voltage-gated ion channels, which provide stability but are limited in input selectivity and coding capacity (Egorov et al., 2002; Major and Tank, 2004; Tseng and O'Donnell, 2005). Network mechanisms contribute to persistent activity by recurrent synaptic feedback through AMPARs or NMDARs, which provide greater input selectivity and coding capacity but are less stable. In addition, to generate persistent activity within networks, prior learning that establishes appropriate synaptic connections is required (Shu et al., 2003; Major and Tank, 2004; Tseng and O'Donnell, 2005; Wang et al., 2013). Since NMDARs conduct synaptic inputs through voltage-gated slow currents, these receptors can combine the strength of single-cell and network mechanisms to mediate persistent activity that is both specific and robust (Wang, 2001; Major and Tank, 2004; Wang et al., 2013). In our characterization of how Arc affects neuronal properties, we show that only NMDAR function (but not AMPAR function) is regulated by Arc in a way consistent with the distribution of persistent firing patterns among different neurons, while intrinsic excitability is not affected. These findings suggest that Arc may regulate experience-related persistent firing patterns among frontal neurons by modulating NMDAR function, which carries unique advantage for information processing.

Although we found that Arc is required for increased persistent firing patterns following motor training, the neuronal expression of Arc alone, with no prior training (as in our untrained and handled mice), does not result in persistent firing. Therefore, our findings suggest that the level of Arc expression and the type of behavioral experience jointly regulate persistent firing patterns. Loss of Arc in untrained HOM mice does not alter the baseline properties of frontal neurons,
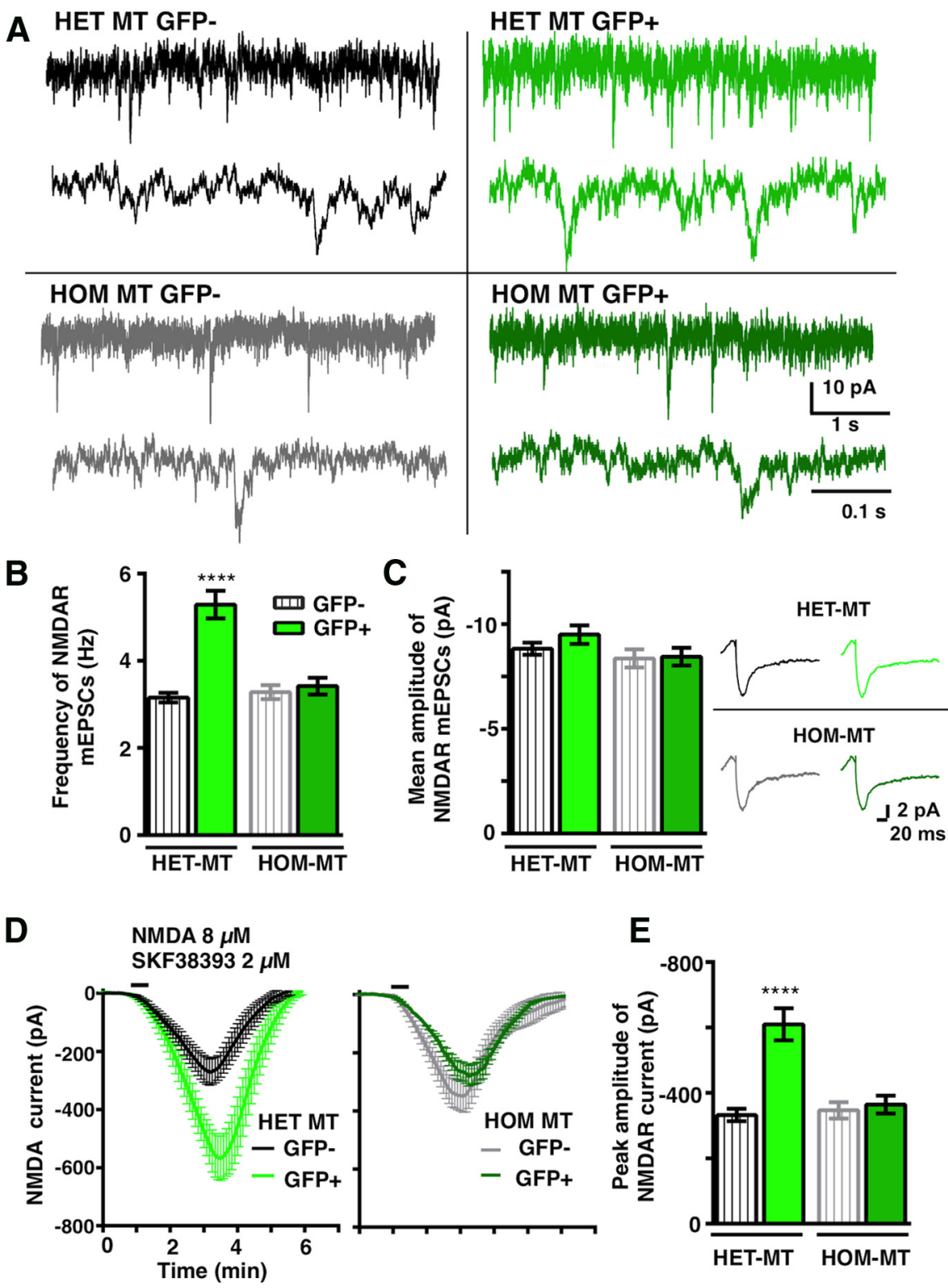

Figure 8. Arc-dependent enhancement of NMDAR function correlates with persistent firing patterns in motor-trained (MT) mice. $A$, NMDAR-mediated mEPSC traces in GFP + and GFP - neurons from HET (7 mice) and HOM (6 mice) MT animals. Miniature NMDAR currents were recorded at holding potential of $-70 \mathrm{mV}$ with TTX $(1 \mu \mathrm{M})$, CNQX (20 $\mu \mathrm{m})$, and bicuculline (20 $\mu \mathrm{m})$ in magnesium-free ACSF. The bottom trace in each subpanel shows individual NMDAR mEPSC events at an expanded time scale. $\boldsymbol{B}$, The frequency of NMDAR-mediated mEPSC s increased significantly in GFP + neurons from ArcHET mice, while the remaining three groups showed similar levels. Two-way ANOVA, genotype-cell-type interaction, $F_{(1,35)}=21.44, p<0.0001$. Neuron numbers: HET MT GFP - , 12; HET MT GFP + , 10; HOM MT GFP - , 7; HOM MT GFP + , 10. C, Left, NMDAR-mediated mEPSCs showed similar mean amplitude in all four neuron groups. One-way ANOVA, $F_{(3,35)}=1.670, p=0.1912$. Right, Average NMDAR mEPSC traces for each of the four groups. D, NMDAR-mediated current evoked by a brief perfusion ( $30 \mathrm{~s}$; black bar) of NMDA ( $8 \mu \mathrm{m})$ and SKF38393 $(2 \mu \mathrm{M})$ into frontal slices. Neurons were recorded in voltage-clamp mode at $-70 \mathrm{mV}$ in the presence of TTX (1 $\mu \mathrm{m})$, bicuculline (20 $\mu \mathrm{M})$, and CNQX (20 $\mu \mathrm{M})$ in magnesium-free ACSF. Each trace is averaged from all the neurons in each experimental group. $\boldsymbol{E}_{,}$ Quantification of the peak amplitude of evoked NMDAR currents in GFP + and GFP - neurons from HET (5 mice) and HOM (5 mice) MT animals shows that NMDAR current is significantly larger in HET MT GFP + neurons. Two-way ANOVA, genotype-cell-type interaction, $F_{(1,62)}=13.93, p=0.0004$. Neuron numbers: HET GFP - , 16; HET GFP + , 19; HOM GFP - , 15; HOM GFP + , 16. All the data are mean \pm SE. Post-tests, ${ }^{* * * *} p<0.0001$.

including intrinsic membrane excitability and AMPAR function, nor does it affect normal induction of experience-dependent gene expression by motor training. The impact of Arc becomes evident, however, when animals are challenged to learn a new motor task. Without Arc function, the training experience failed to result in persistent firing in specific frontal neurons. Since NMDAR-mediated current is increased only in neurons with 


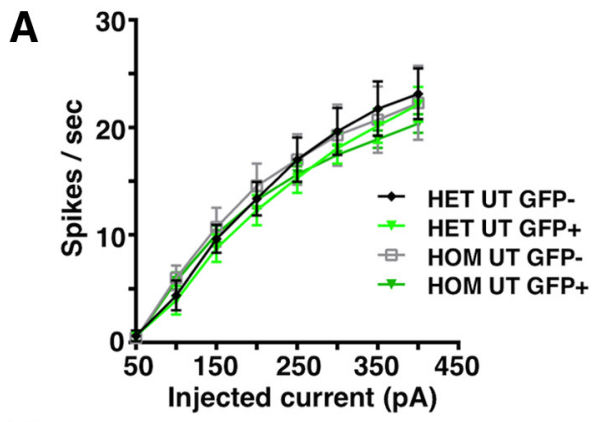

B
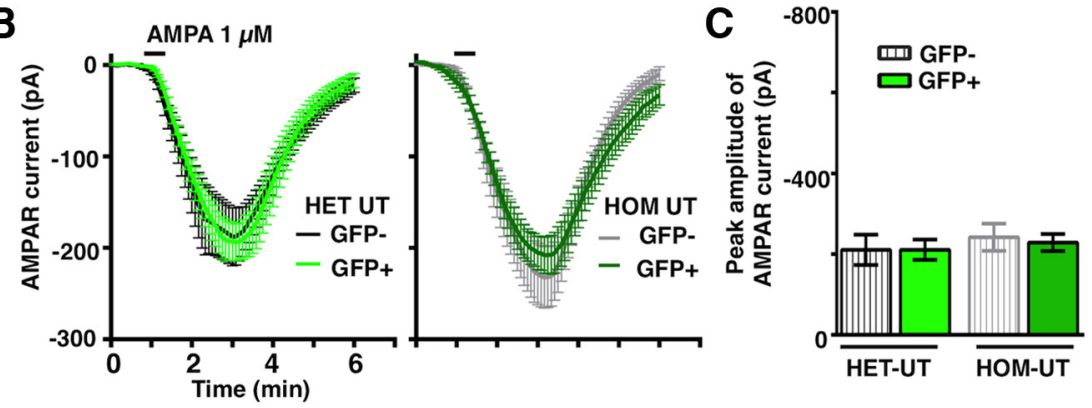

D

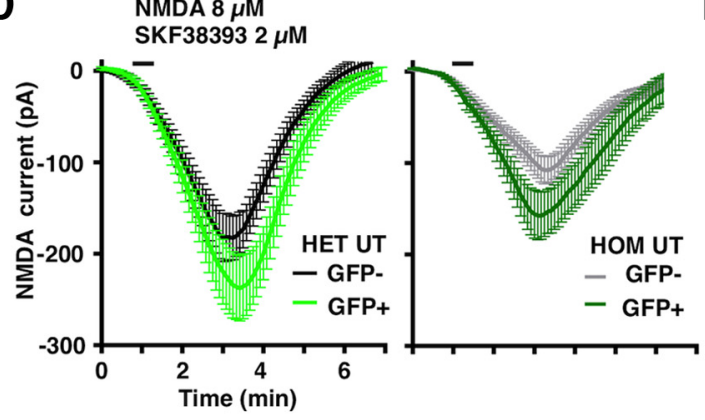

E

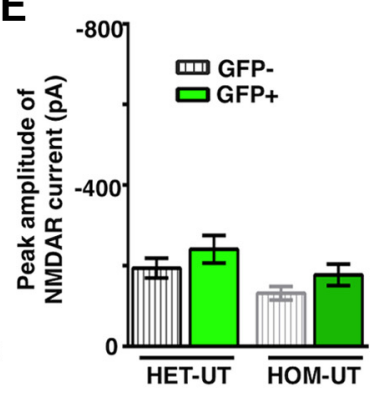

Figure 9. Neuronal properties in the untrained (UT) mice. $\boldsymbol{A}$, Input- output curve of injected currents versus number of spikes. GFP + and GFP - neurons from HET ( 8 mice) and HOM (8 mice) UT animals were recorded in the current-clamp mode, and action potentials were induced by current injection $(500 \mathrm{~ms})$. No significant difference in input- output relationship among the four groups. Two-way repeatedmeasures ANOVA, group effect, $F_{(3,36)}=0.2260, p=0.8777$; group-currentinteraction, $F_{(21,252)}=1.123, p=0.3238$. Neuron numbers: HET UT GFP- , 8; HET UT GFP + , 14; HOM UT GFP- ,7; HOM UT GFP + ,11. B, AMPAR-mediated current evoked by a brief perfusion ( $30 \mathrm{~s}$; black bar) of AMPA $(1 \mu \mathrm{m})$ into frontal slices. Slices were pretreated with cyclothiazide (100 $\mu \mathrm{m})$ to prevent AMPAR desensitization. Neurons were recorded in the voltage-clamp mode at $-70 \mathrm{mV}$ in the presence of TTX (1 $\mu \mathrm{m})$ and bicuculline $(20 \mu \mathrm{m})$ in ACSF. Each trace is averaged from all the neurons in each experimental group. C, Quantification of the peak amplitude of evoked AMPAR currents shows no group difference in GFP + and GFP - neurons from HET ( 5 mice) and HOM (5 mice) UT animals. One-way ANOVA, $F_{(3,38)}=0.2479, p=$ 0.8623. Neuron numbers: HET UT GFP- 11; HET UT GFP + , 11; HOM UT GFP- , 10; HOM UT GFP + , 10. D, NMDAR-mediated current evoked by a brief perfusion ( $30 \mathrm{~s}$; black bar) of NMDA $(8 \mu \mathrm{m})$ and SKF38393 $(2 \mu \mathrm{m})$ into frontal slices. Neurons were recorded in the voltage-clamp mode at $-70 \mathrm{mV}$ in the presence of $\mathrm{TTX}(1 \mu \mathrm{m})$, bicuculline $(20 \mu \mathrm{m})$, and CNQX $(20 \mu \mathrm{m})$ in magnesium-free ACSF. Each trace is averaged from all the neurons in each experimental group. $\boldsymbol{E}$, Quantification of the peak amplitude of evoked NMDAR currents shows that NMDAR currents were similar between GFP + and GFP - neurons in either HET ( 5 mice) or HOM ( 5 mice) UT animals. The average level of NMDAR current in HOM UT mice is lower than that in HET UT mice. Two-way ANOVA, genotype effect, $F_{(1,38)}=6.054, p=0.0185$; GFP cell-type effect, $F_{(1,38)}=3.266, p=0.0786$. Neuron numbers: HET UT GFP - , 10; HET UT GFP + , 10; HOMUT GFP - , 12; HOM UT GFP +, 10. All the data are mean $\pm \mathrm{SE}$.

Table 2. Intrinsic membrane properties of neurons from untrained mice

\begin{tabular}{|c|c|c|c|c|}
\hline & $\begin{array}{l}\text { HET untrained } \\
\text { GFP- }\end{array}$ & $\begin{array}{l}\text { HET untrained } \\
\text { GFP + }\end{array}$ & $\begin{array}{l}\text { HOM untrained } \\
\text { GFP- }\end{array}$ & $\begin{array}{l}\text { HOM untrained } \\
\text { GFP+ }\end{array}$ \\
\hline Resting potential (mV) & $-66.6 \pm 0.6$ & $-66.6 \pm 0.6$ & $-65.91 \pm 0.8$ & $-66.9 \pm 0.6$ \\
\hline $\begin{array}{l}\text { Threshold for action } \\
\text { potential (mV) }\end{array}$ & $-40.6 \pm 1.1$ & $-40.5 \pm 1.4$ & $-41.1 \pm 0.7$ & $-40.7 \pm 1.1$ \\
\hline Input resistance $(\mathrm{M} \Omega$ ) & $174.2 \pm 14.9$ & $181.5 \pm 11.7$ & $176.7 \pm 10.6$ & $190.3 \pm 12.9$ \\
\hline Rheobase current (pA) & $130 \pm 14.3$ & $136 \pm 16.6$ & $135 \pm 8.9$ & $125 \pm 8.7$ \\
\hline Cell number & 9 & 10 & 10 & 11 \\
\hline
\end{tabular}

The intrinsic membrane properties of GFP + and GFP - neurons prepared from Arc HET ( 6 mice) or HOM (5 mice) untrained animals were comparable among groups. One-way ANOVA, resting potential, $F_{(3,36)}=0.6606, p=$ 0.5817 ; threshold for action potential, $F_{(3,36)}=0.08243, p=0.9692$; input resistance, $F_{(3,36)}=0.2665, p=$ 0.8491 ; rheobase current, $F_{(3,36)}=0.1377, p=0.9368$. motor-training-induced Arc expression, Arc may interact with other motortraining-induced molecular changes to enhance NMDAR function in individual Arc-expressing neurons, thereby promoting persistent firing patterns. Previous biochemical studies reported the association of Arc protein with the NMDAR complex in the postsynaptic density (Husi et al., 2000), but whether Arc modulates NMDAR function remained unknown. This study therefore reveals a hitherto unrecognized Arc-dependent molecular pathway by which gene-experience interaction regulates the NMDAR-mediated persistent firing patterns in specific neuronal populations.

In contrast to the relatively little work done previously on Arc and NMDAR function, extensive research has focused on Arc's role in regulating AMPARs. Those studies showed that Arc protein interacts with the endocytic vesicle proteins dynamin and endophilin, promotes the endocytosis of AMPAR, and weakens the synaptic AMPAR response (Chowdhury et al., 2006; Rial Verde et al., 2006; Shepherd and Bear, 2011). Despite these findings, it is difficult to predict the overall level of AMPAR function in Arcexpressing neurons, which is influenced by a variety of experience-regulated factors other than Arc. Those factors may promote increases in AMPAR function and counteract Arc's effects (Yassin et al., 2010; Okuno et al., 2012; Jakkamsetti et al., 2013). In our own experiments, we found that while AMPAR function is altered in HOM mice compared with HET mice, the distribution of AMPAR current levels between GFP + and GFP - neurons from HET and HOM mice does not correlate with that of persistent firing patterns. These findings suggest that it is unlikely that Arc regulates persistent firing patterns through AMPARs.

Persistent neuronal activity is associated with a variety of cognitive functions (such as attentional selection, working memory, response preparation, and memory consolidation), whether as a means of keeping current information readily accessible or reactivating information stored in brain circuits (Fuster, 2001; Miller and Cohen, 2001; Egorov et al., 2002; Major and Tank, 2004; TakeharaNishiuchi and McNaughton, 2008; Hahn et al., 2012). To modulate persistent activity and cognition, it is important to understand the underlying molecular mechanisms. Investigating these mechanisms during cognitive tasks in vivo remains a significant technical challenge (Williams and Goldman-Rakic, 1995; Wang et al., 2013). Although reduced brain slice systems do not fully recapitulate network conditions in vivo, the key molecular players and microcircuitry components are preserved and can be studied under better-controlled experimental conditions (Major and Tank, 2004; 
Haider and McCormick, 2009). It is possible that additional network mechanisms based on long-range feedback connections may contribute to some of the more prolonged persistent activity observed in vivo yet absent from slice preparations, but the molecular mechanisms related to NMDAR-mediated persistent activity generated in local microcircuitry can be examined in this slice preparation.

To mimic the natural environment for frontal neurons and to initiate persistent firing, we used NMDA and D1R agonist in the slice medium, as reported in several earlier studies (Seamans and Yang, 2004; Tseng and O'Donnell, 2005; Stewart and Plenz, 2006; Durstewitz and Gabriel, 2007). Our study reveals a new molecular pathway in which Arc regulates the enhancement of NMDARmediated persistent firing patterns in frontal neurons after training. It remains to be investigated in future research whether training experience and Arc will affect persistent activity generated under other experimental conditions (Major and Tank, 2004; Haider and McCormick, 2009). In addition, our findings raise interesting questions about the projection targets of those Arc-expressing neurons and the endurance of their firing pattern changes. Because the GFP construct in the Arc-GFP knock-in mouse line was destabilized to capture the dynamics of Arc gene regulation, Arc-GFP fluorescence does not light up axons or last into the next day (Wang et al., 2006). New genetic-labeling tools that ensure both low baseline expression and stable induction after behavioral training may help address those questions about Arc-expressing neurons (Guenthner et al., 2013). At the behavioral level, the impairment of long-term motor learning we observed in Arc HOM mice implies a role of Arc, and possibly persistent firing, in consolidating motor memory. Our study suggests that molecular genetic strategies targeting the function of the Arc gene or Arc-expressing neurons (Silva et al., 2009; Guenthner et al., 2013) may be used to modulate persistent activity and dissect its contributions to cognitive functions.

Deficits in NMDAR-signaling pathways and frontal persistent activity have long been implicated in the pathophysiology of psychiatric disorders (Meyer-Lindenberg and Weinberger, 2006; Castner and Williams, 2007; Lewis and González-Burgos, 2008). More recently, NMDAR-signaling and Arc-signaling complex have been shown as the prime targets of mutations in psychiatric disorders, such as schizophrenia (Fromer et al., 2014; Purcell et al., 2014). Shedding new light on the Arc protein's role in NMDAR-mediated persistent activity may therefore provide an important step toward the identification of new therapeutic targets for the treatment of neuropsychiatric diseases. Our experimental framework, in which behavioral training is combined with ex vivo slice physiology and optical imaging, may facilitate the identification and validation of new candidate molecular targets.

\section{References}

Barth AL (2007) Visualizing circuits and systems using transgenic reporters of neural activity. Curr Opin Neurobiol 17:567-571. CrossRef Medline

Barth AL, Poulet JF (2012) Experimental evidence for sparse firing in the neocortex. Trends Neurosci 35:345-355. CrossRef Medline

Barth AL, Gerkin RC, Dean KL (2004) Alteration of neuronal firing properties after in vivo experience in a FosGFP transgenic mouse. J Neurosci 24:6466-6475. CrossRef Medline

Bramham CR, Worley PF, Moore MJ, Guzowski JF (2008) The immediate early gene $\operatorname{arc/arg3.1:~regulation,~mechanisms,~and~function.~J~Neurosci~}$ 28:11760-11767. CrossRef Medline

Buitrago MM, Schulz JB, Dichgans J, Luft AR (2004) Short and long-term motor skill learning in an accelerated rotarod training paradigm. Neurobiol Learn Mem 81:211-216. CrossRef Medline

Castner SA, Williams GV (2007) Tuning the engine of cognition: a focus on
NMDA/D1 receptor interactions in prefrontal cortex. Brain Cogn 63:94122. CrossRef Medline

Chowdhury S, Shepherd JD, Okuno H, Lyford G, Petralia RS, Plath N, Kuhl D, Huganir RL, Worley PF (2006) Arc/Arg3.1 interacts with the endocytic machinery to regulate AMPA receptor trafficking. Neuron 52:445459. CrossRef Medline

Costa RM, Cohen D, Nicolelis MA (2004) Differential corticostriatal plasticity during fast and slow motor skill learning in mice. Curr Biol 14: 1124-1134. CrossRef Medline

Dalley JW, Cardinal RN, Robbins TW (2004) Prefrontal executive and cognitive functions in rodents: neural and neurochemical substrates. Neurosci Biobehav Rev 28:771-784. CrossRef Medline

Durstewitz D, Gabriel T (2007) Dynamical basis of irregular spiking in NMDA-driven prefrontal cortex neurons. Cereb Cortex 17:894-908. Medline

Egorov AV, Hamam BN, Fransén E, Hasselmo ME, Alonso AA (2002) Graded persistent activity in entorhinal cortex neurons. Nature 420:173178. CrossRef Medline

Erlich JC, Bialek M, Brody CD (2011) A cortical substrate for memoryguided orienting in the rat. Neuron 72:330-343. CrossRef Medline

Farr TD, Liu L, Colwell KL, Whishaw IQ, Metz GA (2006) Bilateral alteration in stepping pattern after unilateral motor cortex injury: a new test strategy for analysis of skilled limb movements in neurological mouse models. J Neurosci Methods 153:104-113. CrossRef Medline

Fromer M, Pocklington AJ, Kavanagh DH, Williams HJ, Dwyer S, Gormley P, Georgieva L, Rees E, Palta P, Ruderfer DM, Carrera N, Humphreys I, Johnson JS, Roussos P, Barker DD, Banks E, Milanova V, Grant SG, Hannon E, Rose SA, et al. (2014) De novo mutations in schizophrenia implicate synaptic networks. Nature 506:179-184. CrossRef Medline

Fuster JM (1973) Unit activity in prefrontal cortex during delayed-response performance: neuronal correlates of transient memory. J Neurophysiol 36:61-78. Medline

Fuster JM (2001) The prefrontal cortex-an update: time is of the essence. Neuron 30:319-333. CrossRef Medline

Guenthner CJ, Miyamichi K, Yang HH, Heller HC, Luo L (2013) Permanent genetic access to transiently active neurons via TRAP: targeted recombination in active populations. Neuron 78:773-784. CrossRef Medline

Guzowski JF, Timlin JA, Roysam B, McNaughton BL, Worley PF, Barnes CA (2005) Mapping behaviorally relevant neural circuits with immediateearly gene expression. Curr Opin Neurobiol 15:599-606. CrossRef Medline

Hahn TT, McFarland JM, Berberich S, Sakmann B, Mehta MR (2012) Spontaneous persistent activity in entorhinal cortex modulates corticohippocampal interaction in vivo. Nat Neurosci 15:1531-1538. CrossRef Medline

Haider B, McCormick DA (2009) Rapid neocortical dynamics: cellular and network mechanisms. Neuron 62:171-189. CrossRef Medline

Histed MH, Pasupathy A, Miller EK (2009) Learning substrates in the primate prefrontal cortex and striatum: sustained activity related to successful actions. Neuron 63:244-253. CrossRef Medline

Holschneider DP, Maarek JM, Yang J, Harimoto J, Scremin OU (2003) Functional brain mapping in freely moving rats during treadmill walking. J Cereb Blood Flow Metab 23:925-932. Medline

Husi H, Ward MA, Choudhary JS, Blackstock WP, Grant SG (2000) Proteomic analysis of NMDA receptor-adhesion protein signaling complexes. Nat Neurosci 3:661-669. CrossRef Medline

Jackson ME, Homayoun H, Moghaddam B (2004) NMDA receptor hypofunction produces concomitant firing rate potentiation and burst activity reduction in the prefrontal cortex. Proc Natl Acad Sci U S A 101:84678472. CrossRef Medline

Jakkamsetti V, Tsai NP, Gross C, Molinaro G, Collins KA, Nicoletti F, Wang KH, Osten P, Bassell GJ, Gibson JR, Huber KM (2013) Experienceinduced Arc/Arg3.1 primes CA1 pyramidal neurons for metabotropic glutamate receptor-dependent long-term synaptic depression. Neuron 80:72-79. CrossRef Medline

Lewis DA, González-Burgos G (2008) Neuroplasticity of neocortical circuits in schizophrenia. Neuropsychopharmacology 33:141-165. CrossRef Medline

Luscher C, Malenka RC (2012) NMDA receptor-dependent long-term potentiation and long-term depression (LTP/LTD). Cold Spring Harb Perspect Biol 4 pii:a005710. CrossRef Medline 
Major G, Tank D (2004) Persistent neural activity: prevalence and mechanisms. Curr Opin Neurobiol 14:675-684. CrossRef Medline

Meyer-Lindenberg A, Weinberger DR (2006) Intermediate phenotypes and genetic mechanisms of psychiatric disorders. Nat Rev Neurosci 7:818827. CrossRef Medline

Miller EK, Cohen JD (2001) An integrative theory of prefrontal cortex function. Annu Rev Neurosci 24:167-202. CrossRef Medline

Okuno H, Akashi K, Ishii Y, Yagishita-Kyo N, Suzuki K, Nonaka M, Kawashima T, Fujii H, Takemoto-Kimura S, Abe M, Natsume R, Chowdhury S, Sakimura K, Worley PF, Bito H (2012) Inverse synaptic tagging of inactive synapses via dynamic interaction of Arc/Arg3.1 with CaMKIIbeta. Cell 149:886-898. CrossRef Medline

Peebles CL, Yoo J, Thwin MT, Palop JJ, Noebels JL, Finkbeiner S (2010) Arc regulates spine morphology and maintains network stability in vivo. Proc Natl Acad Sci U S A 107:18173-18178. CrossRef Medline

Plath N, Ohana O, Dammermann B, Errington ML, Schmitz D, Gross C, Mao X, Engelsberg A, Mahlke C, Welzl H, Kobalz U, Stawrakakis A, Fernandez E, Waltereit R, Bick-Sander A, Therstappen E, Cooke SF, Blanquet V, Wurst W, Salmen B, et al. (2006) Arc/Arg3.1 is essential for the consolidation of synaptic plasticity and memories. Neuron 52:437-444. CrossRef Medline

Purcell SM, Moran JL, Fromer M, Ruderfer D, Solovieff N, Roussos P, O’Dushlaine C, Chambert K, Bergen SE, Kähler A, Duncan L, Stahl E, Genovese G, Fernández E, Collins MO, Komiyama NH, Choudhary JS, Magnusson PK, Banks E, Shakir K, et al. (2014) A polygenic burden of rare disruptive mutations in schizophrenia. Nature 506:185-190. CrossRef Medline

Rial Verde EM, Lee-Osbourne J, Worley PF, Malinow R, Cline HT (2006) Increased expression of the immediate-early gene $\operatorname{arc} / \arg 3.1$ reduces AMPA receptor-mediated synaptic transmission. Neuron 52:461-474. CrossRef Medline

Sah P, Hestrin S, Nicoll RA (1989) Tonic activation of NMDA receptors by ambient glutamate enhances excitability of neurons. Science 246:815818. CrossRef Medline

Seamans JK, Yang CR (2004) The principal features and mechanisms of dopamine modulation in the prefrontal cortex. Prog Neurobiol 74:1-58. CrossRef Medline

Shepherd JD, Bear MF (2011) New views of Arc, a master regulator of synaptic plasticity. Nat Neurosci 14:279-284. CrossRef Medline

Shu Y, Hasenstaub A, McCormick DA (2003) Turning on and off recurrent balanced cortical activity. Nature 423:288-293. CrossRef Medline

Sidiropoulou K, Lu FM, Fowler MA, Xiao R, Phillips C, Ozkan ED, Zhu MX, White FJ, Cooper DC (2009) Dopamine modulates an mGluR5mediated depolarization underlying prefrontal persistent activity. Nat Neurosci 12:190-199. CrossRef Medline

Silva AJ, Zhou Y, Rogerson T, Shobe J, Balaji J (2009) Molecular and cellular approaches to memory allocation in neural circuits. Science 326:391-395. CrossRef Medline

Stewart CV, Plenz D (2006) Inverted-U profile of dopamine-NMDAmediated spontaneous avalanche recurrence in superficial layers of rat prefrontal cortex. J Neurosci 26:8148-8159. CrossRef Medline

Stuber GD, Klanker M, de Ridder B, Bowers MS, Joosten RN, Feenstra MG, Bonci A (2008) Reward-predictive cues enhance excitatory synaptic strength onto midbrain dopamine neurons. Science 321:1690-1692. CrossRef Medline

Suh YH, Terashima A, Petralia RS, Wenthold RJ, Isaac JT, Roche KW, Roche PA (2010) A neuronal role for SNAP-23 in postsynaptic glutamate receptor trafficking. Nat Neurosci 13:338-343. CrossRef Medline

Takehara-Nishiuchi K, McNaughton BL (2008) Spontaneous changes of neocortical code for associative memory during consolidation. Science 322:960-963. CrossRef Medline

Thuault SJ, Malleret G, Constantinople CM, Nicholls R, Chen I, Zhu J, Panteleyev A, Vronskaya S, Nolan MF, Bruno R, Siegelbaum SA, Kandel ER (2013) Prefrontal cortex HCN1 channels enable intrinsic persistent neural firing and executive memory function. J Neurosci 33:1358313599. CrossRef Medline

Tseng KY, O’Donnell P (2005) Post-pubertal emergence of prefrontal cortical up states induced by D1-NMDA co-activation. Cereb Cortex 15:4957. Medline

Vazdarjanova A, Ramirez-Amaya V, Insel N, Plummer TK, Rosi S, Chowdhury S, Mikhael D, Worley PF, Guzowski JF, Barnes CA (2006) Spatial exploration induces ARC, a plasticity-related immediate-early gene, only in calcium/calmodulin-dependent protein kinase II-positive principal excitatory and inhibitory neurons of the rat forebrain. J Comp Neurol 498: 317-329. CrossRef Medline

Wang KH, Majewska A, Schummers J, Farley B, Hu C, Sur M, Tonegawa S (2006) In vivo two-photon imaging reveals a role of arc in enhancing orientation specificity in visual cortex. Cell 126:389-402. CrossRef Medline

Wang M, Yang Y, Wang CJ, Gamo NJ, Jin LE, Mazer JA, Morrison JH, Wang XJ, Arnsten AF (2013) NMDA receptors subserve persistent neuronal firing during working memory in dorsolateral prefrontal cortex. Neuron 77:736-749. CrossRef Medline

Wang XJ (2001) Synaptic reverberation underlying mnemonic persistent activity. Trends Neurosci 24:455-463. CrossRef Medline

Williams GV, Goldman-Rakic PS (1995) Modulation of memory fields by dopamine D1 receptors in prefrontal cortex. Nature 376:572-575. CrossRef Medline

Yassin L, Benedetti BL, Jouhanneau JS, Wen JA, Poulet JF, Barth AL (2010) An embedded subnetwork of highly active neurons in the neocortex. Neuron 68:1043-1050. CrossRef Medline 